\title{
Intraoperative Ultrasound Guided Liver Resections: A Single Center Experience
}

\author{
Florin Botea ${ }^{1}$, Diana Nicolaescu ${ }^{1}$, Alexandru Barcu ${ }^{1}$, Nausica Picu ${ }^{1}$, Alexandru Onofrei ${ }^{1}$, Gabriela Droc ${ }^{2}$, \\ Dana Tomescu' ${ }^{2}$, Vlad Herlea ${ }^{3}$, Irinel Popescu ${ }^{1}$
}

${ }^{1}$ Center of General Surgery and Liver Transplantation, Fundeni Clinical Institute, Bucharest, Romania

${ }^{2}$ Department of Anesthesia and Intensive Care, Fundeni Clinical Institute, Bucharest, Romania ${ }^{3}$ Department of Pathology, Fundeni Clinical Institute, Bucharest, Romania

\section{ABSTRACT}

Background: Liver resection (LR) is the standard treatment for most focal liver lesions. Intraoperative ultrasound (IOUS) improves their diagnosis and guides the liver resection. The present paper analyses our experience in IOUS guided LR, reviewing the indications, surgical techniques, and the short-term results.

Material and Method: 198 LRs guided by IOUS in 186 patients operated in our center between January 2013 and December 2017 were included in a combined prospective and retrospective study. The median age of the patients was 60 years (mean 57, range 16-79), with a male/female ratio of 109/77, and adult/pediatric patient ratio of 185/1.

Results: Malignant lesions were the main indication for IOUS guided LR (164 LRs; $82.8 \%$ ); among these, colorectal liver metastases were the main indication (66 LRs; $33.3 \%$ ), followed by hepatocellular carcinoma (44 cases, 22.2\%). The mean number of tumors was 3 (range 1-16), and the median diameter of the largest tumor was $40 \mathrm{~mm}$ (mean 51; range 3-240). IOUS found new lesions in $22.3 \%$ of cases operated for liver metastases (46 LRs), and changed the surgical strategy in $41.9 \%$ of cases ( $83 \mathrm{LRs}$ ). Major resection rate was $18.2 \%$ (36 LRs); anatomical LRs were performed in 18 cases (9.1\%). The median operative time was 330 minutes (mean 334; range 90-920). The median blood loss was $700 \mathrm{ml}$ (mean 900; range 250-9500), with a transfusion rate of $54.8 \%$ (108 LRs). Overall and major complication rates were $46.5 \%$ (92 LRs) and 7.6\% (15 LRs), respectively, while the mortality rate was $2 \%$ (4 pts).

Conclusion: IOUS should be fully integrated in the modern liver surgery, providing improved diagnosis and optimal resection guidance, increasing resectability and surgical safety, with low perioperative morbidity and mortality.

Key words: liver resection, intraoperative ultrasound, focal liver lesions, single-center experience

\section{BACKGROUND}

The advancement of imaging technology and intraoperative devices, along with the refinement of operative techniques and intensive care protocols played a significant role in increasing the resectability with decreased morbidity and
Corresponding author: Irinel Popescu, MD, PhD, FACS, FEBS Professor of Surgery

Fundeni Clinical Institute Center of General Surgery and Liver Transplantation, Bucharest, Romania Soseaua Fundeni 258, Bucharest Romania

E-mail: irinel.popescu220@gmail.com

\author{
Abbreviations \\ CT - computed tomography \\ $\mathrm{FLL}$ - focal liver lesions \\ FRL - future remnant liver \\ HCC - hepatocellular carcinoma \\ HV - hepatic vein \\ IOUS - intraoperative ultrasound \\ LR - liver resection \\ LM -liver metastases \\ MRI - magnetic resonance imaging
}


mortality. Somehow surprising, even though the first applications of intraoperative ultrasound (IOUS) were recorded in the '50s, IOUS entered liver surgery more recently, mainly due to the Japanese school of surgery, represented by M. Makuuchi (1).

Despite advances in preoperative imaging techniques (MRI, CT, etc.) in the past decades, IOUS remains the most accurate diagnostic method for hepatic focal lesions, especially in case of liver metastases (LM), when the overall accuracy in detecting the lesions is about $95 \%$, significantly superior to the preoperative imaging (about 75\%) (2). However, the nodule detection may be impaired by liver steatosis or may be falsely increased by the cirrhotic liver; in these situations, the use contrastenhanced in IOUS may surpass the difficulties (3).

However, if diagnostic IOUS is currently widely diffused worldwide, the IOUS guidance of LR is not, very few centers outside Japan having adopted it, the most successful being the one in Italy (Milan), represented by G. Torzilli, that further developed the approach (3). The present paper analyses our experience in IOUS guided $L R$, reviewing the indications, surgical techniques, and the short-term results.

\section{PATIENTS}

A total of 186 pts benefited from 198 LRs performed in our center in the last 5 years (between January 2013 and December 2017). The median age of the patients was 60 years (mean 57, range 16-79), the male/female ratio was $109 / 77$, and adult (over 18 years old)/pediatric patient ratio 185/1. A subgroup of 12 pts (6\%) received repeated LRs: 7 pts (3.5\%) received one re-resection, while 5 pts $(2.5 \%)$ received two re-resections; among these, 2 pts ( $0.1 \%)$ benefited from a two-stage approach (noncurative followed by curative LR), with (1 pt) and without (1 pt) portal vein ligation, one patient received an ALPPS procedure (Associated Liver Partition and Portal vein ligation for Staged hepatectomy). LRs after portal ligation were performed in 3 pts (1.5\%).

Overall, IOUS guided LRs represented $15.6 \%$ of all LRs performed in our center (198 out of 1267 LRs). Overtime, LRs progressively increased as absolute number and proportion of all operations performed in our center, from 40 LRs (13.0\%) in 2013 to 58 LRs (23.1\%) in 2017 $(p<0.01)$ (table 1).

The comorbid conditions were evaluated according to the Charlson Comorbidity Index (CCI) (4), with a median score of 7 (mean 7; range 0-13).
Table 1 - Evolvement of intraoperative ultrasound guided liver resection yearly number

\begin{tabular}{lccc}
\hline Year & $\begin{array}{c}\text { All operations } \\
\text { (No of cases) }\end{array}$ & $\begin{array}{c}\text { Liver resections } \\
\text { (No of cases) }\end{array}$ & $\%$ \\
\hline 2013 & 308 & 40 & 13.0 \\
\hline 2014 & 270 & 33 & 12.2 \\
\hline 2015 & 216 & 28 & 13.0 \\
\hline 2016 & 222 & 39 & 17.6 \\
\hline 2017 & 251 & 58 & 23.1 \\
\hdashline TOTAL & 1267 & 198 & 15.6 \\
\hline
\end{tabular}

\section{METHODS}

We analyzed an HPB database with data collected prospectively (preoperative and intraoperative data) and retrospectively (postoperative data) from the medical records of patients undergoing IOUS guided LR in our center during the last 5 years. Patient demographics, indications for LR, intraoperative data (tumor location, type of LR, associated procedures, blood loss, blood transfusion, operation time), pathologist report (total number of lesions, largest tumor size and histology), and postoperative data (days of recovery, overall and major complications, and mortality within 90 days from surgery) were recorded and analyzed.

\section{Study end-points}

The primary outcome was the short-term surgical outcome, measured by postoperative complications classified according Dindo-Clavien classification (5), major (at least IIIA class according to the Dindo-Clavien classification) and overall morbidity rates, and 90-day postoperative mortality rates. The secondary end-point of the study was the evaluation of the types of the IOUS guided LR used in the present series.

\section{Preoperative evaluation}

The investigation protocol included liver function tests, specific tumor markers, and imaging, such as contrast abdominal CT scan and/or contrast magnetic resonance imaging (MRI) for the liver, thoracic $\mathrm{CT}$; in selected cases, scintigraphy or positron emission tomography (PET) was considered. All patients were evaluated in our weekly multidisciplinary team meeting including surgeons, radiologists, oncologists, and gastroenterologists.

\section{Intraoperative ultrasound}

\section{Ultrasound device}

IOUS was always performed by the same main 
surgeon, using an Esaote MyLab (Esaote Genova, Italy) with a cross-shaped high frequency $(7.5-10 \mathrm{MHz})$ intraoperative probe, and, more recently, a BK 5000 (BK, Copenhagen, Denmark) with a T-shaped (5-14 MHz) and a biplane (5-12 MHz) high frequency intraoperative probes (fig. 1). The sterilization of the ultrasound probes was accomplished at ethylene oxide gas. The control panel of the ultrasound machine was covered with a sterile transparent plastic film in order to allow ultrasound adjustments by the surgeon. IOUS contrast agent (Sonovue ${ }^{\circledR}$, Bracco, Milan) was used only in few cases. To reduce the use of multiple ultrasound probes, no lower frequencies probes ( 3.5 to $5 \mathrm{MHz}$ ) were used. It is worth mentioning that, in the absence of this probe which provides panoramic image of the liver (which is easier to understand and interpret), the operator needs to have adequate experience in order to be able to exclusively use the reduced field probes, such as the high-frequency ones; in this sense, a high frequency convex probe provides a wider field that a linear one with the same size. The ultrasound system was placed near the first operator, with a transparent sterile cover on the command panel, and was operated mainly by the first operator, and occasionally by the third.

\section{IOUS protocol}

The IOUS exploration was always preceded by liver mobilization consisting in dividing the round, falciform and triangular ligaments in order to expose the entire liver surface for a complete exploration by inspection and palpation (mandatory for subcapsular nodule detection), followed by ultrasound exam, which is essential for the detection of nodules undetected at inspection \& palpation.

IOUS included three main stages:

I. Evaluation of liver anatomy

II. Tumor staging and background liver assessment

III. LR guidance, which includes three steps:
a. planning the proper $L R$
b. guiding the $L R$
c. checking the post-LR.

\section{Liver anatomy}

IOUS was of paramount importance in evaluating the intrahepatic liver vasculature (glissonian pedicles and hepatic veins) and its anatomical variants, establishing the segmental and subsegmental liver anatomy.

A first step consisted in the assessment of liver anatomy, initiated by placing the probe on the central part of the liver (segment 4) at the level of the main portal bifurcation and continued by following the two main portal pedicles and their corresponding segmental and subsegmental pedicles, and then by following the three hepatic veins (HVs) towards the hepatocaval confluence, thus delineating the liver segments.
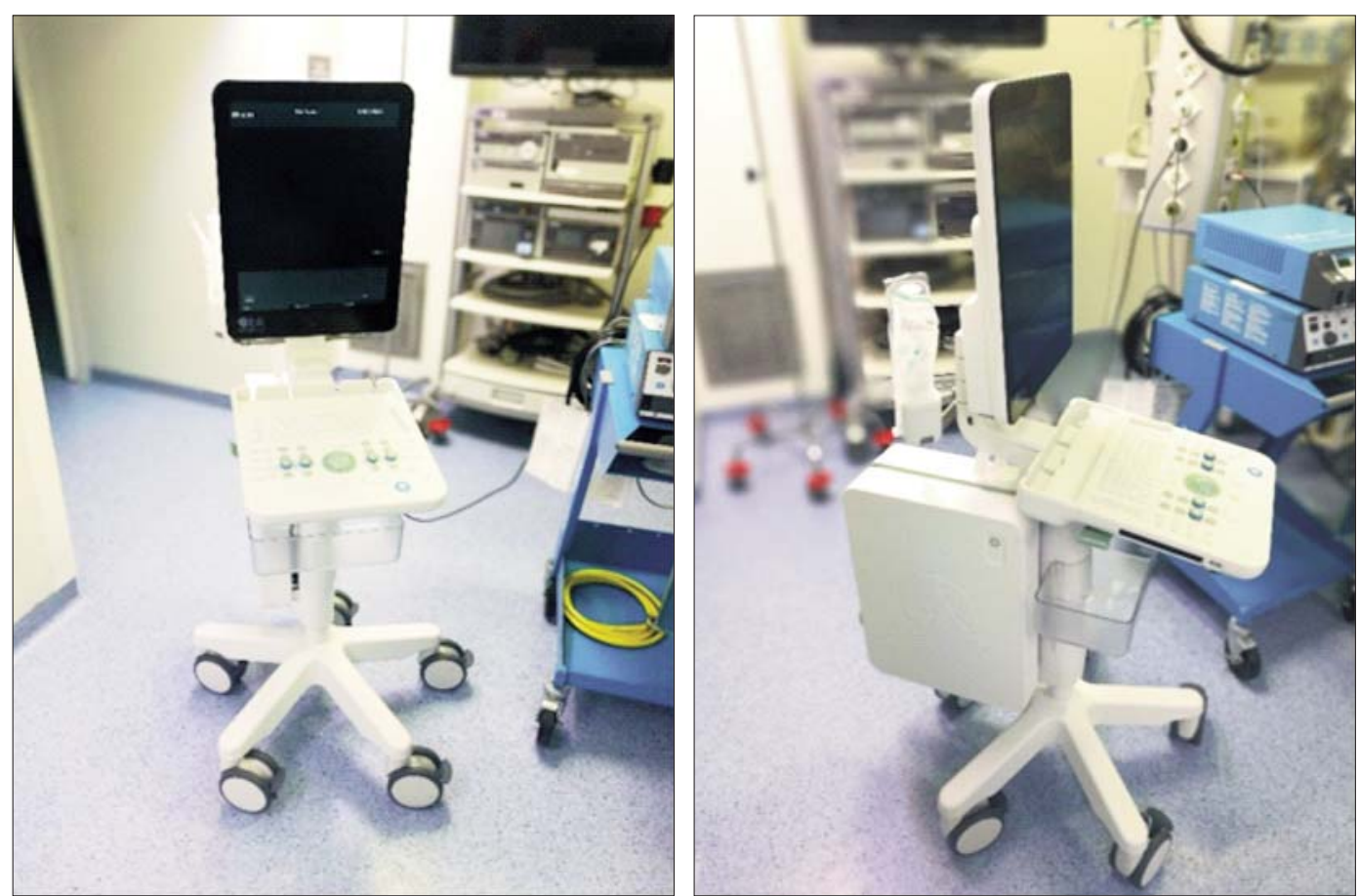

Figure 1 - BK 5000 ultrasound machine (BK, Copenhagen, Denmark) with a T-shaped (5-14 MHz) and a biplane (5-12 MHz) high frequency intraoperative probes 


\section{$\underline{\text { Tumor staging and background liver assessment }}$}

The second stage of IOUS protocol was represented by the diagnostic stage, in which all the focal liver lesions (FLLs) signaled preoperatively were mapped and potentially new ones were detected, including the differential ultrasound diagnosis of each FLL. For a complete examination, the probe covered the entire accessible liver surface, and IOUS exploration was combined with visual exploration and palpation of the liver. Contrast enhanced IOUS was rarely included in the exploration protocol.

\section{Surgical strategy}

Patients with acceptable performance status, resectable liver disease, absence of extrahepatic disease, and sufficient future remnant liver volume (FRL) (at least $30 \%$ of total liver volume in case of normal liver parenchyma, or at least $40 \%$ in case of steatotic or cirrhotic liver) were considered suitable for LR. In cirrhotic patients, Child A cirrhosis, no significant portal hypertension, and platelets count of more than 100.000 were used as selection criteria for LR; if intraoperatively the macroscopic aspect of the liver revealed a more advanced cirrhosis that previously considered, the operation was often shifted to a tumor ablation procedure. Our pivotal surgical policy was to preserve as much liver parenchyma as possible in all cases. In case of malignant tumors, a free margin of the resected specimen was always considered to be at least of $1 \mathrm{~mm}$; in case of FLLs in contact with large vessels, tumor exposure in this particular area was accepted (6) in order to insure resectability by maximizing the FRL. For the same purpose, association of resection with different methods of tumor ablation (ethanol, radiofrequency or microwave ablation) was used in 18 (9\%) small deep located malignant FLLs (12 LM and 6 HCC): 9 nodules of up to $5 \mathrm{~mm}(4.5 \%)$, and other 9 of up to 2 $\mathrm{cm}(4.5 \%)$.

\section{Guidance of liver resection}

IOUS was used to guide the resection plane in all cases, in such manner to include the targeted lesions in the resected specimen while preserving the vascularization and bile drainage for the remnant liver. In case of non-anatomical LR, the resection area was delineated on the diaphragmatic surface using ultrasound guidance: the tip of the electrocautery was positioned between the ultrasound probe and the liver surface (fig. 2), placed in the four cardinal points in such manner to surround the targeted FLLs with safety margins in case of malignancy (accepted as few millimeters or even 0 when major intrahepatic vascular structures in contact with a FLL was to be preserved (6)); these points were then joined to delimit the resection area on the liver surface with the electrocautery (fig. 2).
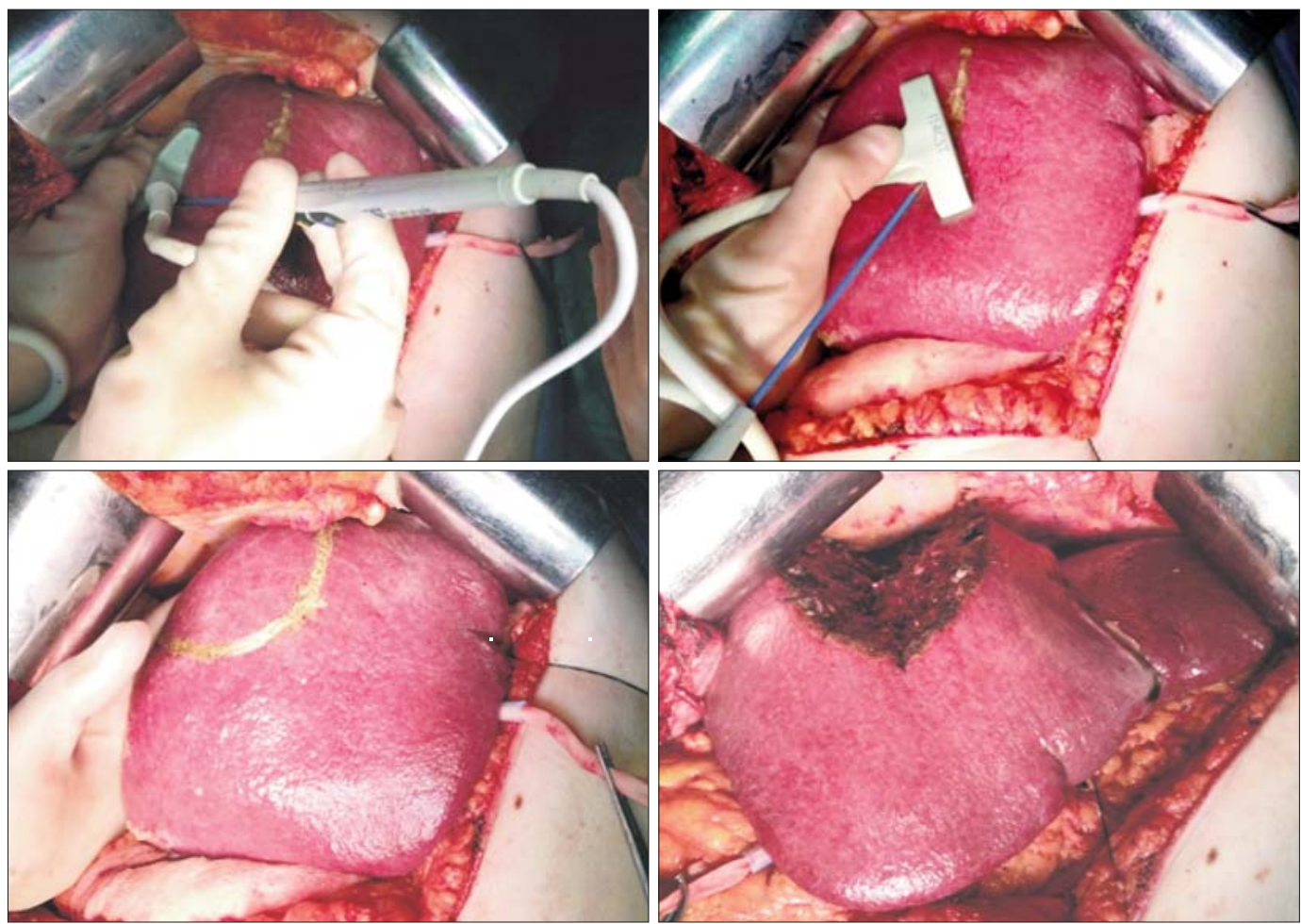

Figure 2 - IOUS guided delineation of the resection area for a S8 resection for HCC on micronodular cirrhosis 

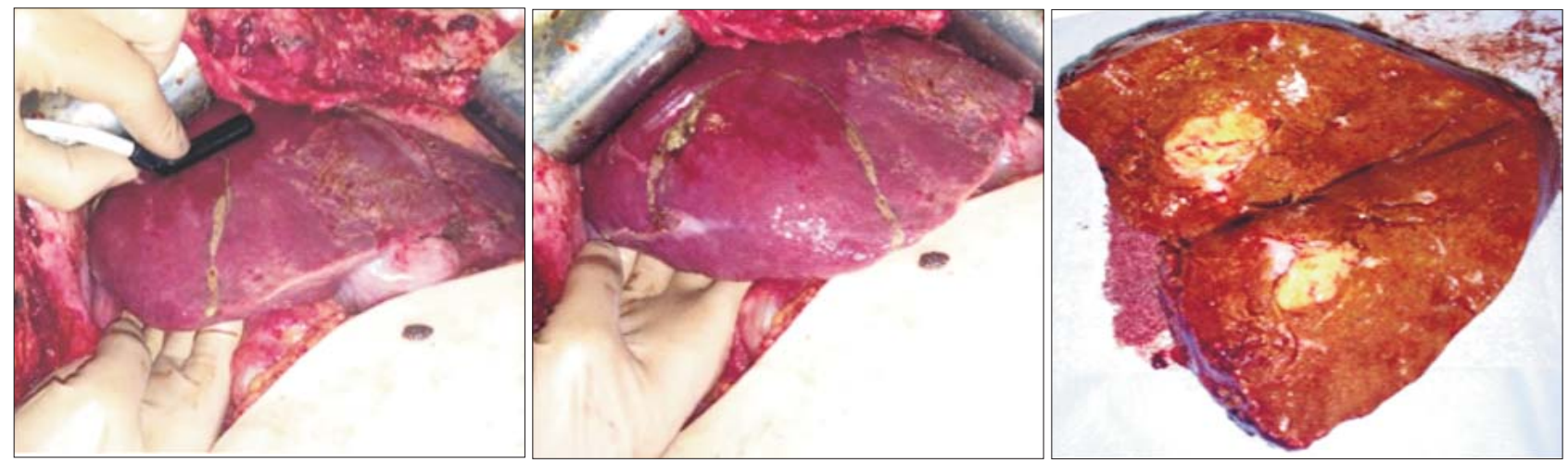

Figure 3 - IOUS guided delineation of the resection area for a marginal non-anatomical segment $6 \& 7$ resection for a colorectal liver metastasis

In case of marginal non-anatomical $L R$, the resection area was determined by placing the tip of the electrocautery between the ultrasound probe on the diaphragmatic liver surface, and the surgeon's finger on the visceral surface, in such manner to define a resection plane in between the two, including the target FLLs along with safety margins (fig. 3).

After the start of the resection, IOUS was used to guide the parenchymal transection plane, which was viewed as an irregular hyperechoic line, due to the presence of air and coagulated blood between the two cut surfaces (remnant liver and specimen) (fig. 4). Using IOUS, the relationship between the tumor edges and the transection plane was followed in real time, and the direction of this plane was modified when needed. Thus, intricate transection plane around the tumors could be devised in order to avoid tumor exposure while sparing important vascular structures along with the corresponding
Figure 4 - IOUS guided non-anatomical segments 2, 3 and 4 for a capsulated HCC in contact with the portal pedicle for segment 3 and the horizontal portion of the left portal vein. Note the white line with a whitish shadow (indicated by arrow) that depicts the tip of a Pean clamp that guides the resection plane identifying the vessel which is in contact with (in this case, the portal pedicle for segment 3 )

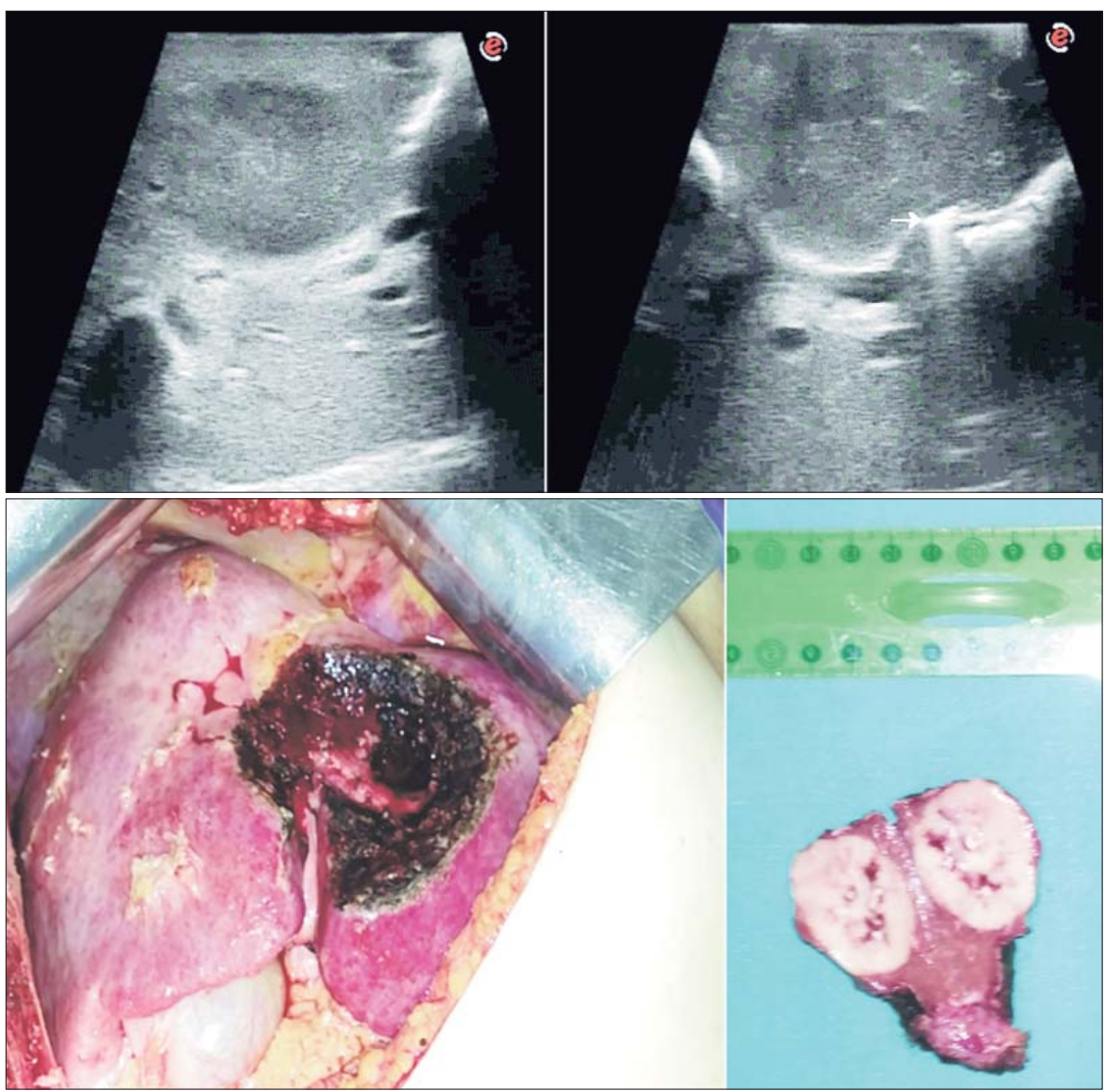


Figure 5 - Segmentectomy of segment 3 for a colorectal liver metastasis invading the segmental pedicle, IOUS certified that the dissected pedicle was the only one belonging to segment 3

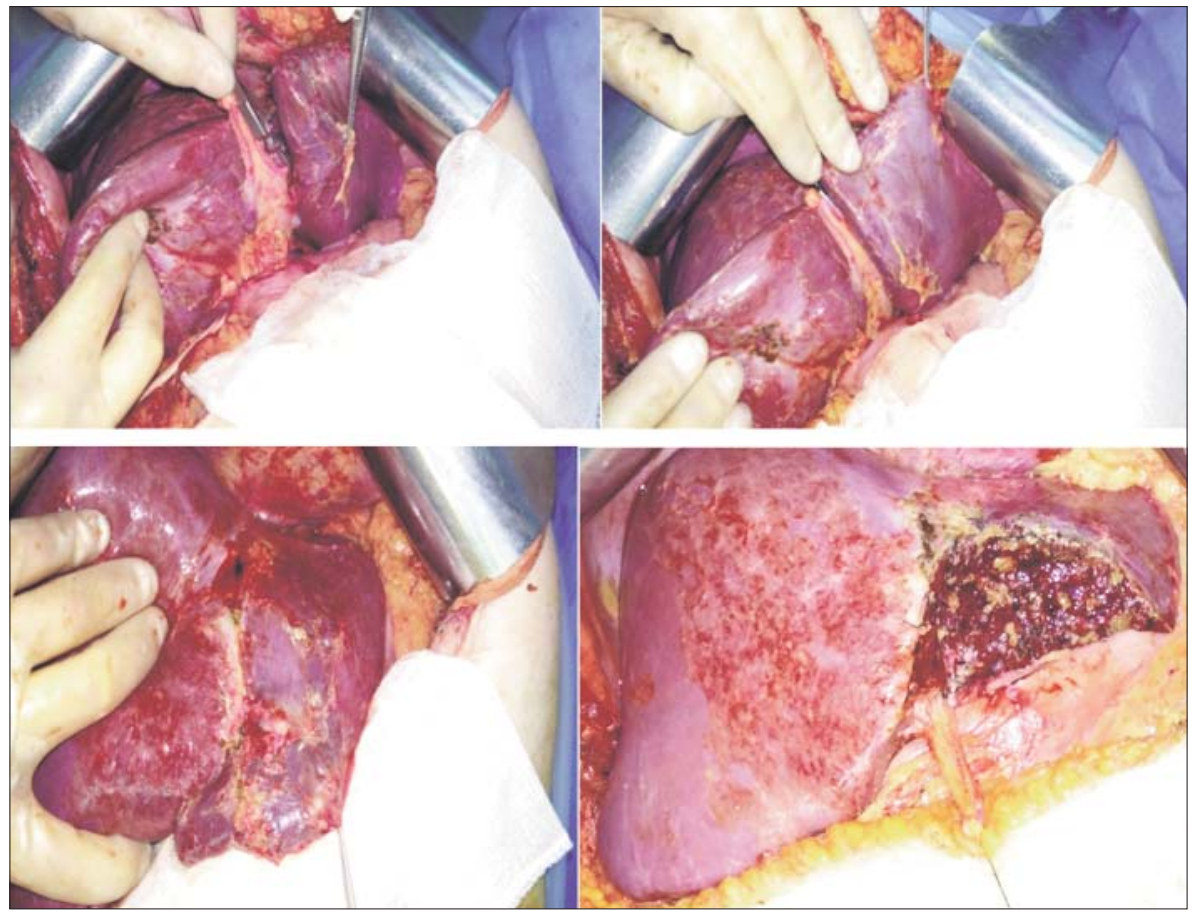

liver parenchyma. This approach was according to the "radical but conservative" approach (7). During resection, any vessel with significant size exposed at the level of the transection plane could be identified at IOUS by the hooking technique (8): a surgical thread was placed around the target vessel which is visualized by a hyperechoic line or point with a rear shadow cone; under a gentle traction of the thread, the encircled vessel is detected at IOUS due to its angulation and occlusion. More often, we used a personal trick consisting in the placement of the tip of a clamp in contact with the vessel to be identified, which was consequently detected at IOUS using as marker the tip of the clamp (fig. 4). The advantages of this trick over the hooking technique is the easiness of detection of tip of a clamp at IOUS (in comparison with the thread placed around the vessels, that needs to be pulled repeatedly) and the fact that the vessel to be identified do not need to be encircled (maneuver that exposes to risk of injury, that is to be avoided in case the vessel needs to be preserved).

In case of anatomical LR, the area was delineated by direct clamping (fig. 5) or by IOUS guided digital compression consisting in the compression of the portal branch (corresponding to the hepatic segments / subsegment to be resected) between the ultrasound probe and the finger of the surgeon, thus obtaining visual delineation of the area to be resected (fig. 6). In patients that required sectionectomies or major hepatectomies, IOUS allowed the design of the transection plane along the middle or right portal fissure, avoiding the inadvertent injuries of the main HVs. In these patients, IOUS guided the extraglissonian approach of portal pedicles, by identifying the anatomical variants, guiding their dissection.

\section{Control of results after LR}

The IOUS control consisted in the control of

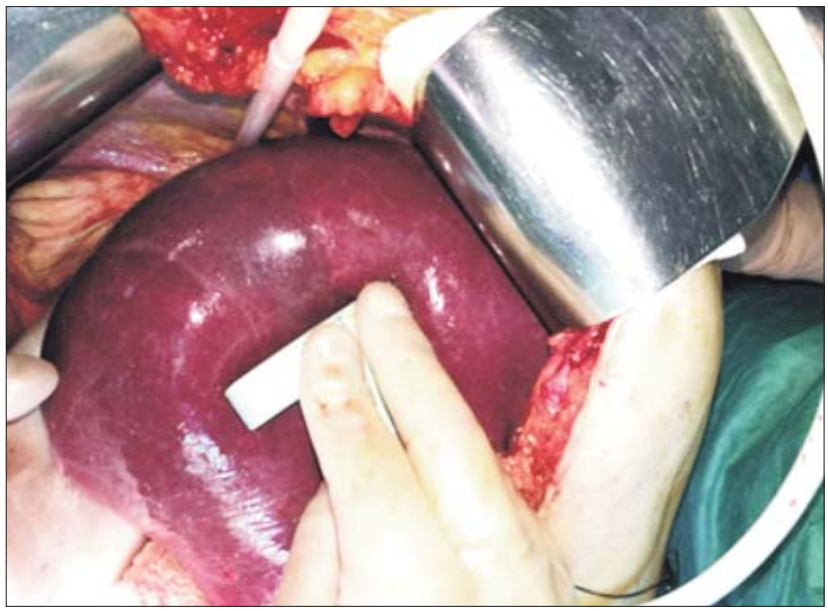

Figure 6 - Subsegmental segment 7 ischemia induced by IOUS guided finger compression of the corresponding subsegmental portal pedicle (originating from P8) that delineates the border between segment 7 and segment 8 . In this case, a right posterior sectionectomy was performed for a deep located HCC in segments 6 and 7 on HBV chronic hepatitis 


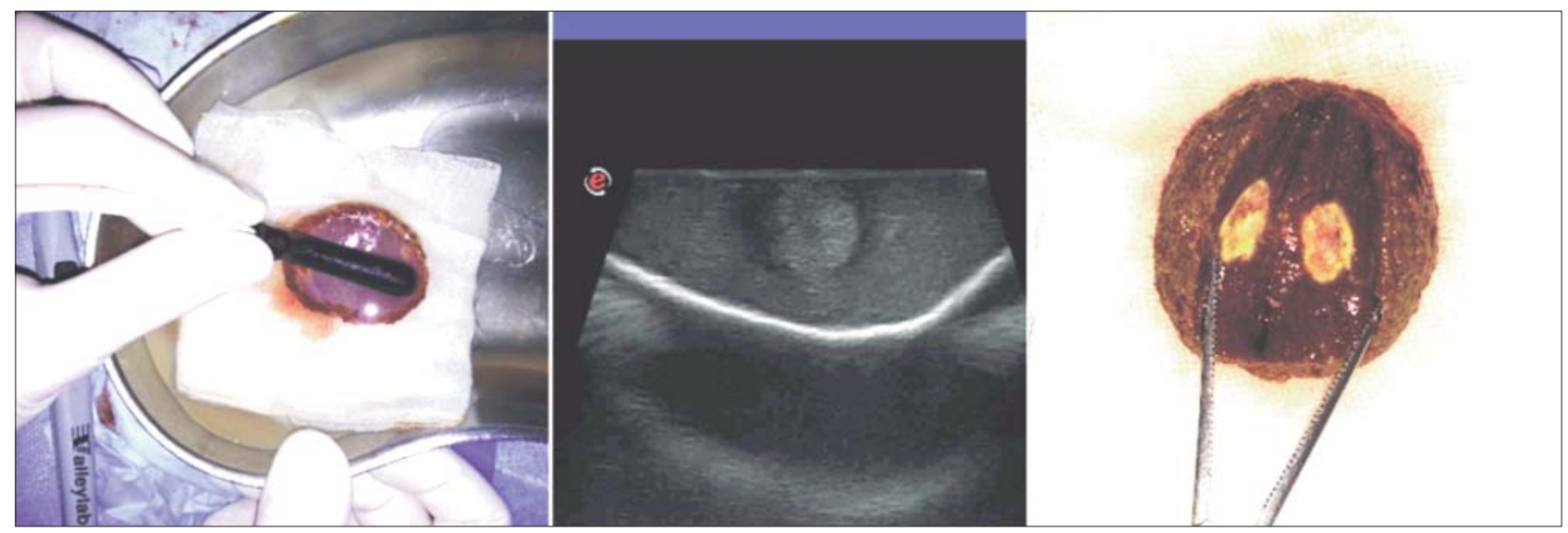

Figure 7 - The "bath" technique for verifying the presence in the resected specimen of the targeted lesion, a small (6 mm) non-palpable colorectal liver metastasis with a $5 \mathrm{~mm}$ resection margin.

the remnant liver for tumor clearance and functional vascularization and bile drainage, and control of the resected specimen (immersed in sterile saline solution the "bath" technique) for the presence of targeted small lesions and their oncological safety margins (fig. 7).

\section{Surgical technique}

The approach was open, routinely through a right subcostal incision that was transformed in case of large and/or multiple bilobar tumors in a Mercedes incision, and rarely through a J-shaped incision (9) (when a thoracotomy was anticipated, or in case of previous upper midline incision). In order to improve the access to the hepatocaval confluence, the xiphoid process was routinely removed. The type of resection was classified according to the anatomical nomenclature of Brisbane 2000 terminology of liver anatomy and resections (10). Major LR was defined as the removal of at least three segments. All established surgical techniques were deployed: anatomical/non-anatomical, major/minor resections; extra/intra-glissonian, extra/intra-parenchymal approach; special strategies to increase resectability, such as liver-first, two-stage, including associated liver partition and portal ligation for staged hepatectomy (ALPPS). Usually, LR was always preceded by liver mobilization. In order to facilitate the hemihepatectomies, the hanging maneuver described by Belghiti et al (11) was used whenever considered fit by the surgeon. Frequently, during right hemihepatectomies, a modified hanging maneuver was deployed, consisting in passing the tape after complete right hemiliver mobilization, sectioning the hepatocaval ligament and the right accessory HVs, and exposing the right HV at its confluence, thus avoiding the bleeding risk from the blind blunt dissection in front of the inferior vena cava.
The liver transection was exclusively performed by using the clamp crushing method (Kelly-clasia) (12), combining ligations (4.0 or 2.0 non-absorbable multifilament suture, depending on the width of the pedicle to be ligated), sutures (4.0 to 6.0 nonabsorbable monofilament suture for vessels, 4.0 to 6.0 absorbable monofilament suture for bile ducts, and 3.0 or 4.0 absorbable multifilament suture for parenchyma), and use of mono-polar cautery. To limit the backflow bleeding from the HVs during liver transection, the central venous pressure was maintained whenever feasible bellow $5 \mathrm{mmHg}$. For vascular control, on demand intermittent portal pedicle clamping (Pringle maneuver) was routinely used deployed in periods of maximum 15 minutes of inflow occlusion with interposed intervals of liver reperfusion of minimum 5 minutes, in order to limit the ischemia-reperfusion injury; furthermore, for FLLs located in the right posterior section, the right $\mathrm{HV}$ was routinely controlled by tourniquet placement, and its occlusion was deployed on demand. The criteria for on demand vascular control were excessive bleeding during liver transection and/or blood loss that exceeded $500 \mathrm{ml}$. Total vascular exclusion was rarely used, in case of LR associated with inferior vena cava resection of the inferior vena cava. Bleeding and bile-leak control on the liver cut-surface was carried out using sutures, monopolar, and hemostatic adjuvants: the preferred was the fibrin sealant patch, but we also used autologous fibrin sealant (Vivostat ${ }^{\circledR}$; Alleroed), synthetic peptides gel (Purastat ${ }^{\circledR}$; Diagmed Healthcare), or oxidized regenerated cellulose (Surgice ${ }^{\circledR}$, Ethicon). It is worth mentioning that we almost never used hemostatic adjuvants to stop active bleeding, but only to secure the hemostasis.

In LRs for large benign lesions during which significant 
bleeding was anticipated, we successfully used the autologous blood recovery system (Cell Saver ${ }^{\circledR}$ ); Haemonetics) in few cases.

Even though the routine use of abdominal drainage after LR has been challenged, and many centers do not drain in these cases anymore (13) (14), we always used drains, supporting this "old-fashioned" policy.

Technically demanding LRs (complex LRs) were defined based on the following criteria:

- Tumor feature: diameter of at least $10 \mathrm{~cm}$ and/or more than 3 bilobar lesions;

- Background liver parenchyma: cirrhosis

- Type of LR: resection (anatomical / non-anatomical) of the middle segments (segments 4, 5, 8); right posterior sectionectomy (segments 6, 7) and non-anatomic extended (to the anterior section and/or segment 1) right posterior sectionectomy, isolated segmentectomy 1 ; transversal hepatectomy (segment 4, 5, 6); non-anatomic extended hemihepatectomies; trisectionectomies; twostage hepatectomy; ALPPS

- Associated resection: portal/arterial/ inferior vena cava resection and reconstruction, biliary resection and reconstruction, other organ resection;

\section{Postoperative outcome}

All postoperative complications occurred 90 days after surgery were recorded and classified according to Dindo-Clavien classification et al (5). Complications leading to life-threatening conditions (grade IIIA and above) were classified as major; these included postoperative bleeding, abscess, sepsis, any organ failure. Complications with no fatal potential were considered minor, such as wound infection, pleural effusion (including the ones that required percutaneous drainage), atelectasis, urinary tract infection. Liver-related complications were defined as all complications directly related with the LR, such as bile leak, cut-surface hematoma or abscess, hemoperitoneum, ascites, liver failure; self-limited bile leak was also considered a minor complication. The major complication rate was calculated based on the most severe complication for each LR. Operative mortality was defined as death during surgical procedure or within 90 post-operative days. Longterm follow-up was carried out depending on their underlying pathological condition, but was not an endpoint of this study. Survival status was established by review of the medical records and defined as the time interval between the date of $L R$ and the date of last patient evaluation or date of death (if known).

\section{Statistical analysis}

Continuous parameters were expressed as median, mean and ranges. Categorical variables were expressed in absolute number and percentage. The MannWhitney test was applied to compare nonparametric data and the chi-squared test or Fisher's exact test were applied for analysis of categorical variables. The level of statistical significance was set at $<0.05$.

\section{RESULTS}

\section{Indications for $L R$}

The indications for IOUS guided LR are depicted in table 2.

IOUS found new lesions in $22.3 \%$ of cases operated for LM (46 cases) (fig. 8). The median number of resected lesions was 1 (mean 2.6; range 1-16); 42 LRs (21.2\%) were performed for more than 3 FLLs. The median diameter of the main lesion was $40 \mathrm{~mm}$ (mean 51; range 3-240); 23 LRs (11.6\%) were performed for lesions larger than $100 \mathrm{~mm}$. Lesions were most frequently located in the right hemiliver (92 LRs; 46.5\%) (table 3). The background liver is described in table 4 .

\section{LR technique}

The surgical approach was always open using a right

Table 2 - Type of resected lesions as diagnosed at pathology

\begin{tabular}{lcc}
\hline Tumor type & No of cases & $\%$ \\
\hline Malignant tumors & 158 & 79.8 \\
\hline Colorectal liver metastases & 66 & 33.3 \\
\hdashline Hepatocellular carcinoma & 44 & 22.2 \\
\hline Other malignant tumors & 12 & 6.1 \\
\hline Non-colorectal liver metastases & 19 & 9.6 \\
\hline Peripheral cholangiocarcinoma & 7 & 3.5 \\
\hline Klatskin tumor & 7 & 3.5 \\
\hline Gallbladder cancer & 2 & 1.0 \\
\hline Hepatoblastoma & 1 & 0.5 \\
\hline Benign tumors & 26 & 13.1 \\
\hline Haemangioma & 13 & 6.6 \\
\hdashline Adenoma & 5 & 2.5 \\
\hdashline Focal nodular hyperplasia & 4 & 2.0 \\
\hline Other benign tumors & 4 & 2.0 \\
\hdashline Other benign lesions & 13 & 6.6 \\
\hdashline Liver hydatid cyst & 6 & 3.0 \\
\hline Liver abscess & 6 & 3.0 \\
\hline Caroli disease & 1 & 0.5 \\
\hdashline Liver trauma & 198 \\
\hline TOTAL & & 0.5 \\
\hline
\end{tabular}


Table 3 - Topography of the focal liver lesions

\begin{tabular}{lcc}
\hline Lesion topography & No of LRs & $\%$ \\
\hline Right hemiliver & 92 & 46.5 \\
\hline Left hemiliver & 23 & 11.6 \\
\hline Bilobar & 81 & 40.9 \\
\hdashline Segment 1 (alone) & 2 & 1.0 \\
\hdashline TOTAL & 198 & 100.0 \\
\hline
\end{tabular}

Table 4 - Background liver

\begin{tabular}{lcc}
\hline Background liver & No of LRs & $\%$ \\
\hline Normal liver & 127 & 64.1 \\
\hdashline Liver cirrhosis & 23 & 11.6 \\
\hline Chronic hepatitis & 29 & 14.6 \\
\hline Steatosis & 34 & 17.2 \\
\hline Impaired liver after chemotherapy & 76 & 38.4 \\
\hline
\end{tabular}

Figure 8 - New small non-palpable liver metastasis found at intraoperative ultrasound

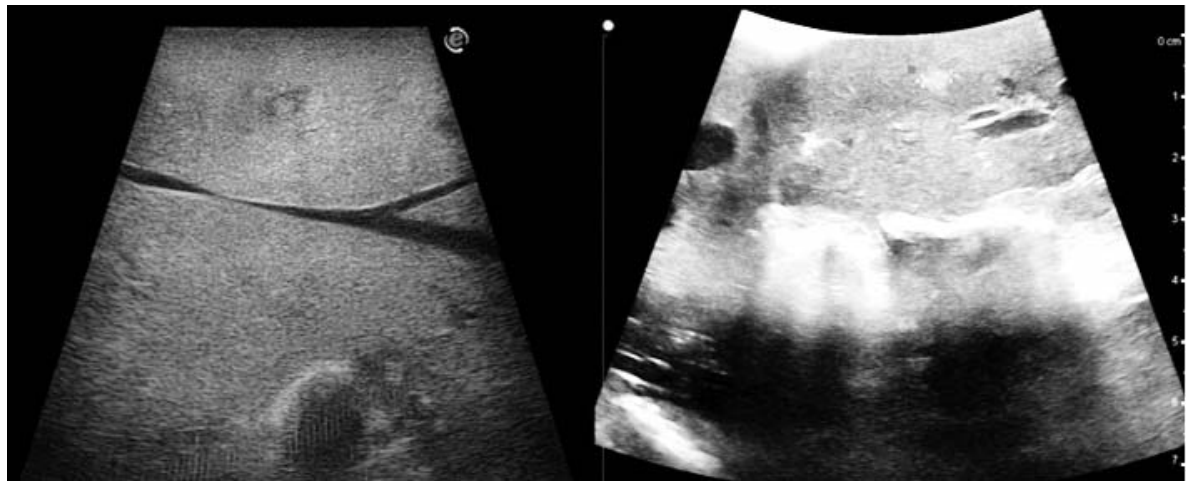

subcostal approach that was transformed in a Mercedes incision in case of multiple bilobar FLLs and/or large FLLs. The J-shaped incision was used only when a previous upper midline incision was present (22 cases; $11.1 \%)$, and a thoraco-laparotomy was used in 2 cases (1\%). IOUS changed the planned LR in 83 cases (41.9\%). Major resection rate was $18.2 \%$ (36 LRs). Anatomical resections were performed in 16 cases (8.1\%) (table 4); out of these, 8 (4\%) had associated limited non-anatomical LRs. According to the established

Table 5 - Type of liver resection (LR)

\begin{tabular}{lcc}
\hline Type of liver resection & No of pts & $\%$ \\
\hline Major resections & 36 & 18.2 \\
\hline Minor resections & 162 & 81.8 \\
\hline Anatomical resections & 16 & 8.1 \\
\hline Trisectionectomy & 2 & 1.0 \\
\hline Right hemihepatectomy & 7 & 3.5 \\
\hline Left hemihepatectomy & 1 & 0.5 \\
\hline Central LR (anatomic) & 2 & 1.0 \\
\hline Bisegmentectomy & 6 & 3.0 \\
\hline Posterior right sectionectomy & 14 & 7.1 \\
\hline Anterior right sectionectomy & 2 & 1.0 \\
\hline Non-anatomical resections & 182 & 91.9 \\
\hline Extended right hemihepatectomy & 12 & 6.1 \\
\hline Extended left hemihepatectomy & 12 & 6.1 \\
\hline Extended bisegmentectomy & 6 & 3.0 \\
\hline Extended right posterior sectionectomy & 7 & 3.5 \\
\hline Central LR (non-anatomic) & 14 & 7.1 \\
\hline Other limited non-anatomical resection & 131 & 66.2 \\
\hline
\end{tabular}

criteria, 112 (56.6\%) were technically complex (table 5). Twenty-three LRs (11.6\%) were performed on cirrhotic liver. Associated ethanol injection and thermal tumor ablation were associated to LR in 9 cases (4.5\%) each. Extrahepatic simultaneously organ resections were performed $10.6 \%$ of cases (21 LRs), among which colorectal resections were performed in $7.6 \%$ of cases (15 LRs). The median operative time was 180 minutes (mean 204; range 45-920). The median operative time was 330 minutes (mean 334; range 90-920). The median blood loss was $700 \mathrm{ml}$ (mean 900; range 2509500), with a transfusion rate of $54.8 \%$ (108 LRs).

\section{Surgical outcome}

Overall and major (at least IIIA according to DindoClavien classification) complication rates were $46.5 \%$ (92 LRs) and 7.6\% (15 LRs), respectively. We underline that pleural effusion that needed percutaneous drainage (4 cases; $2 \%$ ) was not considered a major complication, as pleural effusion is a common complication after LR, the indication for drainage is not standardized, and it does not have a vital risk; moreover, in case of thoraco-laparotomy, pleural effusion needing percutaneous drainage is exceptional, so considering this a major complication would bias the comparison with published data by centers that favor this type of approach.

Among all liver-related complications, cut surface collection were the most frequent (23 LRs; $11.6 \%$ ), 
Table 6.

\begin{tabular}{|c|c|c|}
\hline Complex LR & No of pts & $\%$ \\
\hline \multicolumn{3}{|l|}{ Criteria } \\
\hline $\begin{array}{l}\text { Maximum tumor diameter more than } \\
100 \mathrm{~mm}\end{array}$ & 15 & 7.7 \\
\hline More than 3 bilobar lesions & 42 & 21.2 \\
\hline Liver cirrhosis & 23 & 11.6 \\
\hline $\begin{array}{l}\text { Trisectionectomy, right/left extended } \\
\text { (non-anatomical) hepatectomy, central LR } \\
\text { (anatomical/ non-anatomical), two-stage } \\
\text { hepatectomy, ALPPS }\end{array}$ & 42 & 21.2 \\
\hline Main bile duct resection & 9 & 4.5 \\
\hline Portal resection & 3 & 1.5 \\
\hline Inferior vena cava resection & 2 & 1.0 \\
\hline Other organ resection & 21 & 10.6 \\
\hline \multicolumn{3}{|l|}{ Number of simultaneous criteria } \\
\hline 1 & 82 & 41.4 \\
\hline 2 & 27 & 13.6 \\
\hline 3 & 2 & 1.0 \\
\hline 4 & 1 & 0.5 \\
\hline TOTAL & 112 & 56.6 \\
\hline
\end{tabular}

followed by ascites (19 LRs; 9.6\%) (table 7). Among major complications, cut-surface collection were the most frequent most severe complication after LR ( 2 LRs;
Table 7 - All liver-related complications recorded after LR

\begin{tabular}{lcc}
\hline Liver-related complications & No of LRs & $\%$ \\
\hline Cut surface collection & 23 & 11.6 \\
\hdashline Bile leakage & 14 & 7.1 \\
\hdashline Ascites & 19 & 96 \\
\hdashline Liver failure & 5 & 2.5 \\
\hdashline Hemoperitoneum & 1 & 0.5 \\
\hline Liver haematoma & 1 & 0.5 \\
\hline Angiocholitis & 1 & 0.5 \\
\hdashline Localized liver necrosis & 0 & 0.0 \\
\hline Vascular thrombosis & 0 & 0.0 \\
\hline
\end{tabular}

1\%) (table 8). Mortality rate was $2 \%$ (4 pts). Median postoperative hospital stay was 8 days (mean 12; range 4-45).

\section{DISCUSSION}

LR is the mainstay treatment for large benign tumors, and primary and metastatic liver tumors, especially in case of colorectal LM (15). Ultrasound is one of the most used imaging techniques in current medical practice, due to its noninvasiveness, rapidity

Table 8 - Dindo-Clavien classification of main complication in each case that benefitted from IOUS guided liver resection

\begin{tabular}{|c|c|c|c|c|c|c|c|c|c|}
\hline & I & II & IIIA & IIIB & IVA & IVB & V & TOTAL & $\%$ \\
\hline \multicolumn{10}{|l|}{ Liver } \\
\hline Bile leakage & 1 & 10 & 1 & 0 & 0 & 0 & 0 & 12 & 6.1 \\
\hline Cut surface collection & 0 & 12 & 2 & 0 & 0 & 0 & 0 & 14 & 7.1 \\
\hline Liver failure & 0 & 1 & 0 & 0 & 0 & 0 & 1 & 2 & 1.0 \\
\hline Angiocholitis & 0 & 1 & 0 & 0 & 0 & 0 & 0 & 1 & 0.5 \\
\hline Hemoperitoneum & 0 & 0 & 0 & 1 & 0 & 0 & 0 & 1 & 0.5 \\
\hline Ascites & 7 & 4 & 0 & 0 & 0 & 0 & 0 & 11 & 5.6 \\
\hline \multicolumn{10}{|l|}{ Respiratory system } \\
\hline Bronchial pneumonia & 0 & 1 & 0 & 0 & 0 & 0 & 0 & 1 & 0.5 \\
\hline Pleural effusion & 0 & 12 & 0 & 0 & 0 & 0 & 0 & 12 & 6.1 \\
\hline Respiratory failure & 0 & 0 & 0 & 0 & 2 & 0 & 1 & 3 & 1.5 \\
\hline \multicolumn{10}{|l|}{ Digestive system } \\
\hline Pancreatic fistula & 0 & 1 & 0 & 0 & 0 & 0 & 0 & 1 & 0.5 \\
\hline Duodenal fistula & 0 & 0 & 1 & 0 & 0 & 0 & 0 & 1 & 0.5 \\
\hline Intestinal Clostridium infection & 0 & 1 & 0 & 0 & 0 & 0 & 0 & 1 & 0.5 \\
\hline \multicolumn{10}{|l|}{ Renal system } \\
\hline Kidney failure & 0 & 3 & 0 & 0 & 2 & 0 & 0 & 5 & 2.5 \\
\hline \multicolumn{10}{|l|}{ Cardiovascular system } \\
\hline Deep vein thrombosis & 0 & 1 & 0 & 0 & 0 & 0 & 0 & 1 & 0.5 \\
\hline \multicolumn{10}{|l|}{ Neurologic system } \\
\hline Neurological disorders & 0 & 1 & 0 & 0 & 0 & 0 & 0 & 1 & 0.5 \\
\hline \multicolumn{10}{|l|}{ Systemic complications } \\
\hline MODS & 0 & 0 & 0 & 0 & 0 & 0 & 2 & 2 & 1.0 \\
\hline Fever & 0 & 11 & 0 & 0 & 0 & 0 & 0 & 11 & 5.6 \\
\hline \multicolumn{10}{|l|}{ Other abdominal complications } \\
\hline Wound infection & 0 & 7 & 0 & 0 & 0 & 0 & 0 & 7 & 3.5 \\
\hline Intraabdominal abscess & 0 & 1 & 0 & 1 & 0 & 0 & 0 & 2 & 1.0 \\
\hline Wound evisceration & 0 & 2 & 1 & 1 & 0 & 0 & 0 & 3 & 1.5 \\
\hline TOTAL & 8 & 69 & 4 & 3 & 4 & 0 & 4 & 92 & 46.5 \\
\hline
\end{tabular}


and repeatability, and has real potential for improvement of performance. Following the experience of IOUS pioneers in liver surgery - Makuuchi M (Japan) (16), Lane RJ (Great Britain) (17), Sigel B (United States) (18), and Bismuth $H$ (France) (19), IOUS became a standard diagnostic tool in liver surgery in the mid-1980s (20), and due to Makuuchi M (Japan), IOUS became a guiding tool in LR (21).

\section{Intraoperative ultrasound}

IOUS of the liver, by removing the "ultrasonic barriers" (such as the abdominal wall or intestinal gas) and the use of high frequency probes $(5-10 \mathrm{MHz})$, has a significant increase in image and diagnostic accuracy due to its unmatched spatial resolution, and therefore remains an essential tool for hepatobiliary surgeons.

IOUS assists the surgeon in assessing intraoperatively with precision and in real time the disease, providing important information for optimal treatment strategy and surgical procedure, including tumor ablation techniques. Furthermore, IOUS optimizes LR by insuring the preservation of proper vascularization and bile drainage of the remnant liver, decreasing significantly the immediate postoperative complications related to ischemic parenchyma, such as liver insufficiency, bile leak, and cut surface abscess. In this way, IOUS guidance also improves the long-term oncological results, as remnant liver ischemia may be associated with early tumor recurrence (22).

Therefore, IOUS brings four major benefits in liver surgery, that have a remarkable impact on surgical management (23), allowing the surgical procedures to be properly changed or adapted, thus avoiding intraoperative incidents or incomplete treatment:

1. Complementary investigation to preoperative imaging methods in depicting the vascular anatomy, liver segmentation and tumor mapping (24);

2. Acquisition of information needed to establish intraoperative tactics and techniques, including tumor vascular invasion or thrombosis (25);

3. Guiding the liver resection (LR) and/or interventional tumor ablation procedures (TA);

4. Verifying the outcome of these procedures, in terms of tumor clearance and proper vascularization and biliary drainage of the remnant liver.

Although there are still skeptical opinions about the usefulness of IOUS in liver surgery (26), many studies have clearly demonstrated its value, stating that modern LR should be ultrasonically guided (21). To the best of our knowledge, our center is the second European center that successfully implemented the
IOUS guided LR in a large series of patients, after the one in Milan (Italy).

\section{Training and learning curve}

IOUS requires a thorough knowledge of general ultrasound, liver anatomy and segmentation, of normal and abnormal findings in the liver $(27,28)$, and of the artifacts that may be encountered in the setting of liver surgery, so a thorough specialized training should be integrated into the surgeon's education program. In this sense, diagnostic IOUS was progressively learned by the main author starting with 2001, during resident ship, while the training in IOUS guidance of LRs was carried out in a high-volume specialized center lead by $\mathrm{G}$. Torzilli (Humanitas Clinical Institute, Milan, Italy) (20062012), during which skills for both LR and IOUS guidance were acquired. The learning curve for IOUS guided LR was covered since 2013 (29), in a highvolume specialized center, under the supervision of an experienced HPB surgeon, I. Popescu.

We emphasize that IOUS, both diagnostic and for LR guidance, was performed by the same surgeon that performed the surgery. In this way we consider that best results, including in terms of decision making and surgical planning, are obtained when diagnostic IOUS is performed by the surgeon and not by the radiologist, while the IOUS guidance during LR can only be performed by the surgeon who performs the LR.

\section{Tumor staging and background liver assessment}

As diagnostic purposes, IOUS can locate preoperatively known liver lesions and detect further FLLs during surgery, thus assisting in planning the type of LR (30). IOUS detects non-palpable FLLs with maximum accuracy and may reveal FLLs undetected at preoperative imaging during intraoperative palpation in $10 \%-35 \%$ of cases (31) (32). Indeed, in our experience, IOUS detected new LM in $22.3 \%$ of cases. On the contrary, IOUS depicts with difficulty superficial (subcapsular) small FLLs, but these are readily detected at intraoperative inspection and palpation. Thus, in order to perform a complete and correct liver assessment, IOUS has to be accompanied by intraoperative inspection and palpation (33). Another scenario in which IOUS has difficulty in depicting small FLLs (under $1 \mathrm{~cm}$ ) are the isoechoic ones (with similar echogenicity as the parenchyma); this situation is usually encountered when exploring a steatotic liver, and may be overcome by the intraoperative use of contrast-enhanced ultrasound agents (3) (34), that we did not routinely performed. Therefore, IOUS should be systematically performed in order not to overlook occult FLLs. When a FLL is identified, its relationship with 
adjacent vascular structures can be accurately assessed by IOUS (35).

IOUS is a key diagnostic tool in LM, reaching a sensitivity unmatched by no other imaging technique, ranging from $93-100 \%$ (36), while MRI or CT has only $84 \%$, and percutaneous ultrasound only $71 \%(23,37)$. IOUS has proven accuracy for the LM detection, with $94 \%$ sensitivity and specificity, 92\% positive predictive value, and $96 \%$ negative predictive value $(38,39)$. In hepatocellular carcinoma (HCC) on cirrhosis, the information provided by IOUS is not always useful for the differential diagnosis with regenerative nodules, so that only $20-30 \%$ of small FLLs detected at IOUS in this scenario are neoplastic (40). Thus, while $84 \%$ of mixt (hyper- and hypoechoic) FLLs are malignant, hypoechoic FLLs are malignant only in $24-30 \%$ of cases, and hyperechoic only in $0-18 \%$ of cases; moreover, the biopsy does not seem to be useful in these situations $(40,41)$. Thus, if mixt FLLs clearly need treatment $(42)$, in case of hypo- or hyperechoic FLLs, only the intraoperative use of contrast-enhanced ultrasound agents may provide a diagnosis $(43,44)$.

IOUS optimizes LR by detecting all lesions and ensuring appropriate oncological safety margin $(45,46)$, thus improving the long-term survival of patients. Consequently, IOUS has become a standard adjuvant method in liver resection (LR) for both primary and secondary tumors $(21,47,48,49)$, having a decisive role in choosing the parenchymal dissection plane in liver resections (43). Information provided by IOUS modified the surgical technique in $19.5-83 \%$ of cases for malignant FLLs $(38,50,51,52,53,54)$. More recent studies report a percentage of $4-7 \%(55,56)$, which may be explained by the advances in preoperative imaging techniques, but especially by the surgical strategy adopted in those studies, with preference for major LR, so that tumors detected de novo at IOUS localized in the resected hemiliver did not influence the surgical technique, at the cost of sacrificing a significant volume of functional liver parenchyma. In case of conservative $L R$, the impact of IOUS on surgical strategy remains particularly important, thus allowing the sacrifice of a minimum volume of functional hepatic parenchyma (7).

It is well known that conventional LR in cirrhotic patients has a high rate of postoperative complications, mainly due to liver failure (up to $64 \%$ of cases) (57). Ability to perform anatomical LR, especially in patients with HCC on cirrhosis, without mortality or major complications (58) is mainly due to the use IOUS (59), which is the best imaging method for staging tumors in the liver and step-by-step guidance of the parenchymal transection. Some authors proved that segmentectomy or subsegmentectomy in HCC is superior in terms of local recurrence compared to non-anatomical limited resection (21). However, in our experience we favored limited non-anatomical LR instead of the anatomical ones.

The presence of portal tumor thrombosis in HCC is no longer an absolute contraindication for LR because it has been demonstrated that long-term survival benefits can be obtained (60). This extension of the surgical guidelines is partly due to the use of IOUS, because in these cases the correct tumor staging and the knowledge of the type of vascular infiltration are fundamental. IOUS guided ligation of the portal pedicle upstream of intravascular tumor thrombosis, reduces the risk of thrombus detachment and migration into the portal system of the remnant liver in 4 cases (2\%).

Tumor mapping and staging was performed by IOUS in all cases of our series. During 46 LRs for colorectal LM (22.3\%), IOUS found 53 new lesions undetected at preoperative imaging. In 67 cases with malignancy $(33.8 \%)$, IOUS found that the preoperatively known FLLs were more locally advanced that previously believed. In 83 of these cases (41.9\%), IOUS modified the surgical strategy and technique. Moreover, IOUS evaluated the quality of liver parenchyma, detecting with ease advanced liver steatosis or fibrosis.

In our series, the majority of resected lesions were malignant (79.8\%). The most common indication for LR was colorectal LM (33.3\%), followed by HCC (22.2\%), in accordance to published data (61). In case of colorectal LM, resection is considered the gold standard treatment and offers the best chance of long-term survival $(62,63)$. In our experience, benign tumors represented only $13.1 \%$ of all LRs, hemangioma being the most frequent indication for $\mathrm{LR}$ among benign lesions (6.6\%). In what the background liver parenchyma is concerned, LR were performed on liver cirrhosis in $11.6 \%$ of cases.

\section{Surgical strategy}

Despite significant advances in preoperative imaging techniques ( $M R I, C T$, etc.) in the last decade, IOUS remains the most accurate diagnostic method for hepatic focal lesions, that often changes surgical planning and patient management $(2,37,23)$. In our series, IOUS changed the surgical planning in $41.9 \%$ of cases, mainly due to new FLLs detected at IOUS and/or more advanced FLLs that was preoperatively considered (increased size, contact/invasion of major vessels, tumor thrombosis). Moreover, IOUS allowed conservative LRs in case of FLL invading one of the main HVs, by documenting compensatory collateral venous circulation 
towards the other(s) HVs and/or centrifugal flow in the corresponding portal pedicles once the involved $\mathrm{HV}$ is temporarily occluded by clamping or IOUS guided digital compression $(64,65)$. The acceptance of minimum oncological resection margin and even tumor exposure when in contact with major vessels significantly increased the resectability. Using these policies, FLLs considered otherwise unresectable, or resectable using more extensive procedures with higher risk of morbidity and mortality, where resected with low morbidity and mortality.

\section{Guidance of liver resection}

IOUS also assisted the LR procedure, by delimitating the resection area, guiding the plane of transection, marking target vascular structures to be sectioned or, on the contrary, preserved (43). IOUS was also used to assess the immediate results after LR, checking the remnant liver for proper vascular flow and tumorclearance. IOUS allowed treatment of small unpalpable lesions in 43 cases (21.7\%). Moreover, IOUS allowed resection of nodules in contact with large vessels insuring tumor exposure only in the area in contact with the respective vessel, scenario that do not expose to significant risk for cut surface tumor recurrence (6). Accidental tumor exposure (tumor exposure when in contact with parenchyma), being encountered in 9 malignant tumors, excluding the capsulated HCC were tumor exposure was accepted. Additional confirmation of the value in IOUS guided LR is proven that the margins of the resected specimens after conventional LR were more frequently infiltrated by tumor (16-18\% of cases) that the ones after IOUS guided LR $(46,66)$. Indeed, in our experience insuring oncological security margins was feasible by IOUS guidance.

\section{Control of results after $L R$}

At control of the remnant liver, IOUS detected remnant nodules in 6 cases (5 cases with multiple bilobar colorectal LM, 1 case with multifocal HCC), and remnant tumor tissue on the cut surface in 3 cases (R2 resection) (1 case with colorectal LM, 1 case with cholangiocarcinoma, and 1 case with infiltrative $\mathrm{HCC}$ ) and assisted in the re-resection of the involved area in all cases insuring a complete tumor removal, except one (multifocal HCC), in which tumor ablation by ethanol injection was performed for a small $(1 \mathrm{~cm})$ residual nodule.

In all but 2 cases, IOUS confirmed the integrity of main biliary and vascular structures of the remnant liver; in these 2 cases, further limited LR was performed in order to excise the impaired parenchyma.

\section{Surgical technique}

\section{Method for parenchymal transection}

A recent randomized controlled trial comparing four different transection methods in liver resection showed that the clamp crushing method remained the most efficient device in terms of resection time, blood loss, and blood transfusion frequency, when compared with CUSA, hydrojet and the dissecting sealer, and was also the least expensive (67). Clamp crushing was the standard method for parenchymal transection in our series of IOUS guided LR not only for its simplicity and efficacy but also for the ability to provide a very versatile method of changing the orientation of the transection plane while insuring a smooth cut surface that is very easy to be depicted at IOUS. Moreover, this method allows a minimum destruction of parenchyma due to the thin clamp, allowing the surgeon to transect in very tight spaces, such a tumor located close to / in contact with a large vessel. Another feature of this method that we consider useful during IOUS guided LR is the "tactile" feedback of the clamp during the crushing movements, allowing differentiating between parenchyma and large vessels, or between parenchyma and tumor tissue during intentional or unintentional tumor exposure.

\section{Intraoperative bleeding}

Despite advances in surgical and anesthetic techniques, blood transfusion is still required in $10-33 \%$ of patients undergoing elective liver resection $(68,69)$. Major bleeding and the subsequent blood transfusion have been shown to increase postoperative morbidity and mortality (70). However, it is debatable whether it is due to a cause-effect relationship or just due to more complex LRs. Perioperative blood transfusions were associated with a higher rate of recurrence and lower survival after LR for early HCC (71), but there we found no clear evidence in case of colorectal LM, peripheral cholangiocarcinoma, and advanced HCC $(71,72)$. Our policy was to reduce blood loss as much as possible by meticulous technique and vascular control by intermittent on demand Pringle maneuver, avoiding massive bleeding in a short period of time. Total vascular exclusion was used in 1 case, in which inferior vena cava thrombectomy was also performed. However, the blood loss was influenced by liver status (cirrhosis and advanced steatosis) $(p=0.03)$ and complexity of $L R(p<0.01)$. The overall transfusion rate in our experience was $54.8 \%$, higher in comparison 
to published data, fact that could be explained by the higher percentage of complex LR (56.6\%).

Lowering the central venous pressure below $5 \mathrm{~cm}$ $\mathrm{H} 2 \mathrm{O}$ in order to decrease the backflow bleeding during LR (73) was used whenever feasible by decreasing the infusions to $1 \mathrm{ml} / \mathrm{kg} / \mathrm{hour}$, the tidal volume to $7 \mathrm{ml} / \mathrm{kg}$, respiratory rate to $12-18 / \mathrm{min}$, the airway pressure below $5 \mathrm{mmHg}$, by patient positioning in antiTrendelenburg (head up), use of diuretics, analgesics and venodilators agents.

\section{Major vs minor hepatectomy}

Major LR represent up to $50 \%$ of LRs performed in the majority of the centers and its decrease in favor of liver parenchyma sparing resection is one of the priorities of liver surgery. This strategy is sometime laborious and time consuming, but increases resectability rate, reduces the morbidity and mortality rates, and often allows future re-resections (74). Consequently, the parenchyma sparing approach in LR has become the standard treatment in colorectal LM $(75,76)$, especially in case of small ones located in the right hemiliver. IOUS guidance significantly facilitates this conservative approach in LR, making feasible LRs that are impossible to perform using the conventional approach. In this sense, we avoided major hepatectomies by replacing them with multiple non-anatomical LR, sectionectomies, extended sectionectomies (such as posterior right sectionectomy extended to the anterior section), or limited central hepatectomy. In our experience, the major resection rate was relatively low (18.2\%) considering the advanved disease presentation of most cases. These findings are consistent with our policy to limit major resections in order to preserve the functional parenchyma as much as possible, avoiding postoperative liver insufficiency and favoring potential re-resections.

\section{Anatomical vs non-anatomical resection}

Anatomical LR is recommended in patients with $\mathrm{HCC}$, according with the theory of cell tumor dissemination through the portal branches of the involved liver segment $(77,78,79,80)$. However, this policy is not generally accepted. The best option for an anatomical yet conservative LR in HCC is the subsegmentectomy. IOUS guided subsegmentectomy may be accomplished by tattoo technique or by digital compression, both being proven safe, feasible and effective, the first being however considered as standard procedure (81). We did not systematically perform anatomical LR in HCC, but we performed IOUS guided segmentectomy or subsegmentectomy using direct exposure or digital compression of the corresponding portal pedicle in case of HCC/LM invading the subsegmental portal pedicle in 9 cases.

In colorectal LM, multiple comparative studies of anatomical versus non-anatomical LR showed similar results regarding the status of resection margins, recurrence and survival $(82,83)$. Our policy clearly favored non-anatomical LR (91.9\%), even in HCC. Nonanatomical LR was preferred for maximizing the FRL volume (thus avoiding the risk of liver failure) and minimizing the risk of major biliary and/or vascular injuries. Major anatomical LR was usually performed only in selected cases with focal lesions/traumatic extensive laceration involving most of the hemiliver, with malignant tumors invading one the main portal pedicles, and for Klatskin tumors.

In our series, for major hepatectomies, the preferred approach was extra-glissonian (assisted by IOUS) whenever feasible, which we considered more straightforeword when compared to the intra-glissonian approach. For the right sectionectomies, we perform the anatomical resection by primarily dissecting the corresponding pedicle whenever favored by portal anatomy (superficially located anterior or posterior pedicle determined at IOUS), otherwise the preferred approach was trans-parenchymal in the plane of the corresponding portal fissure determined by IOUS. Even though this type of LR is not generally accepted as anatomical, it is logical to admit that, for example, a LR conducted in a IOUS guided plane placed laterally to the right $\mathrm{HV}$, exposing the later, and intersecting the right posterior pedicle at origin, leaving no ischemic tissue on the cut surface, is indeed an anatomical LR. In few cases of right posterior sectionectomy, we used the induced portal ischemia of subsegments of segment 6 and segment 7 adjacent to segment 5 and segment 8 , or counter-portal ischemia of the subsegment 8 dorsal and segment 5 to delineate the resection area, by IOUS guided finger compression of the corresponding pedicles.

\section{Oncological resection margin}

The oncological security margin was initially considered to be of at least $1 \mathrm{~cm}(84,85,86)$. Because of this principle, many patients were considered not resectable, and therefore did not benefit from this treatment. In the new era of chemotherapy, the efficacy of LR for LM with reduced oncological security margin was sustained by numerous studies, proving that the thickness of the surgical margin is at least of $1 \mathrm{~mm}(87,88)$; the concept seems to be also valid in case of HCC (89). More recently, even no surgical margin at all (tumor exposure) was proven not correlated with reduced overall survival in both HCC 
$(90,91)$ and LM, where similar overall survival rates following negative margin status (R0) and microscopically positive margin status (R1) may be obtained using an aggressive approach consisting in combined chemotherapy and repeat surgery (92). Moreover, in case of colorectal LM, pathological studies have proved that micro metastases, satellitosis and Glisson sheath extension are extremely rare $(93,94)$.

It is worth mentioning that the margin status assessment is difficult, being dependent of the transection techniques used that vaporize, aspirate, ablate or fracture the parenchyma adjacent to the tumor, leading to an underestimation of the width of the resection margin; in other words, the more parenchyma is destructed during parenchymal transection, the less width of resection margin may be obtained. Moreover, the pathologist often cannot differentiate between tumor exposure on the resected specimen (R1 margin status) and residual tumor on the liver cut surface (R2 margin status). In this scenario, IOUS guidance offers precision, assisting in avoiding to leave residual tumor on the liver cut surface; moreover, in case that happens, IOUS can detect it during the control of the remnant liver and assists in the re-resection of the involved area, insuring a complete tumor removal. However, tumor biology rather than width of surgical margin seems to correlate with liver recurrence and overall survival.

In our series, in LM the standard approach was to obtain R0 margin status. However, we did not exclude patients from resection if tumor exposure (no security margin) was contemplated in order to preserve major vessels in contact with tumor, and therefore insure resectability. We underline that tumor exposure in contact with parenchyma was avoided and considered an error, according to a policy that was recently validate (6). Moreover, in these particular cases we avoid to leave macroscopic tumor tissue on the remnant liver (macroscopically positive R2 margin status) by using the IOUS guidance; however, in 3 cases IOUS discovered residual tumor on the cut surface and assisted in completing the resection. On the contrary, when tumor invasion was seen at IOUS, an upfront LR including the territory of the invaded vessels was performed whenever feasible. The IOUS criteria for tumor invasion, similar to ones described by Torzilli et al (7), were: intravascular thrombosis, abnormal vessel wall appearance, more than 180 degrees contact between tumor and vessel, and upstream bile duct dilation (in case of portal pedicles). When the main trunk of a major HV was invaded, its territory was not included in the LR when IOUS depicted collateral communicating veins with the adjacent venous territory, such as with middle HV territory when main right $\mathrm{HV}$ resection was contemplated, right $\mathrm{HV}$ and/or left HV territories when main middle HV resection was contemplated, or with middle HV territory when main left HV resection was contemplated), or significant accessory right HV were present when main right $\mathrm{HV}$ resection was contemplated.

\section{Complex liver resection}

In this study, technically complex LRs were identified based on the above-mentioned criteria with the purpose to analyze the disease severity, as well as the surgical expertise. Therefore, almost half of all LRs were complex (47.2\%), meaning that, unfortunately, patients often were referred to surgery in advanced stages necessitating substantial surgical expertise. Complex LR was the main factor influencing the postoperative outcome, with major complication and mortality rate of $11.9 \%$ and $6.5 \%$, respectively, compared to $2.9 \%$ and nil in the rest of the series, respectively $(p<0.01$ and $p<0.01$, respectively). In our opinion, the complexity of LR should always be considered when analyzing the results of a certain series, reflecting both the morbidity rate and the expertise. Moreover, patients with complex presentations of liver tumors should always be evaluated by a multidisciplinary team in a highlyspecialized center, otherwise a significant part of them would be submitted to useless explorative laparotomies, incomplete or risky procedures, or they would not be referred to LR at all.

\section{Vanishing lesions}

The increased use of more effective chemotherapy regimens for downstaging or as neoadjuvant therapy commonly induces the "disappearance" of LM at preoperative imaging. IOUS has a key-role in this situation, as it is able to detect them, even when not detectable at intraoperative exploration and palpation, and more important, to guide their resection, even in case of deep-localized FLLs. It is worth mentioning that steatosis may impair the IOUS capacity to detect small LM. Other approaches in case of vanishing lesions may be: decreased time and/or aggressiveness of chemotherapy, treatment using local ablation techniques combined with fusion imaging, anatomical resection of the involved territory, or "wait and see" treatment strategy. However, IOUS guided LR may be an option, as in all cases of vanished preoperative lesions but one, we successfully detected and treated the lesion; in that particular case, where one of 4 lesions preoperatively known was not detected by IOUS, a re-resection was performed after 6 months during which the lesion along with another new one were resected. 


\section{Increase of resectability}

We applied all strategies to improve resectability in patients unresectable with upfront conventional LR due to large tumor volume that would require the resection of an excessive amount of functional parenchyma, with high risk of liver failure $(95,96)$. However, we favor upfront LR policies (97):

- Two-stage hepatectomy $(98,99)$, recommended in multiple bilobar LMs, The drawbacks are the necessity of two operations (each associated with specific morbidity and mortality) and the failure to perform the second stage due to tumor progression in $19-24 \%$ patients $(98,100)$.

- ALPPS (Associating Liver Partition and PVL for Staged hepatectomy) procedure is a novel surgical technique aimed to induce a the more rapid and robust hypertrophy of the FRL. In the present series one patient with multiple colorectal LM located in the right hemiliver and segment 4 was treated successfully using this procedure, with no recurrence at 9 months after surgery. The role of IOUS was significant in this case, as it discovered several new nodules, including the ones in segment 4, and guided the liver transection plane in such way to exclude the nodules and to preserve as much as possible of segment 4 in the FRL. This proved very useful, as the without postoperative complications maximum hypertrophy obtained after 21 days was borderline (26\%). However, the limitations of this technique are related to the increased rates of major morbidity (up to $40 \%$ ) and mortality (up to 12\%) (101). Indeed, our case had a late wound evisceration that required surgery.

- Multiple liver resections as an alternative to the two stage hepatectomy $(102,103)$, especially in patients with bilobar liver tumors, that were encountered in a significant proportion of our series (40.9\%). The strategy consisted in avoidance of major LRs, replacing them with multiple nonanatomical resections, or segmental oriented minor LR associated with limited non-anatomical resections (fig. 9). The main criticism is represented by narrow resection margins and even a higher incidence of R1 resections, but, as recently proved, tumor exposure when in contact with major vessels is a safe approach (6).

- Replacement of major anatomical hepatectomies with non-anatomical limited LRs. Thus, hemihepatectomy associated with partial resection of the adjacent section was preferred instead of a trisectionectomy, and right posterior sectionectomy associated with partial resection of the anterior section replaced the right hepatectomy (64). For centrally located tumors (segments 4, 5 and 8), an alternative to the central hepatectomy (trisegmentectomy $4,5,8$ ) was a non-anatomical LRs of the tumors located in these segments (fig. 10). The performance of such a hepatectomy, which

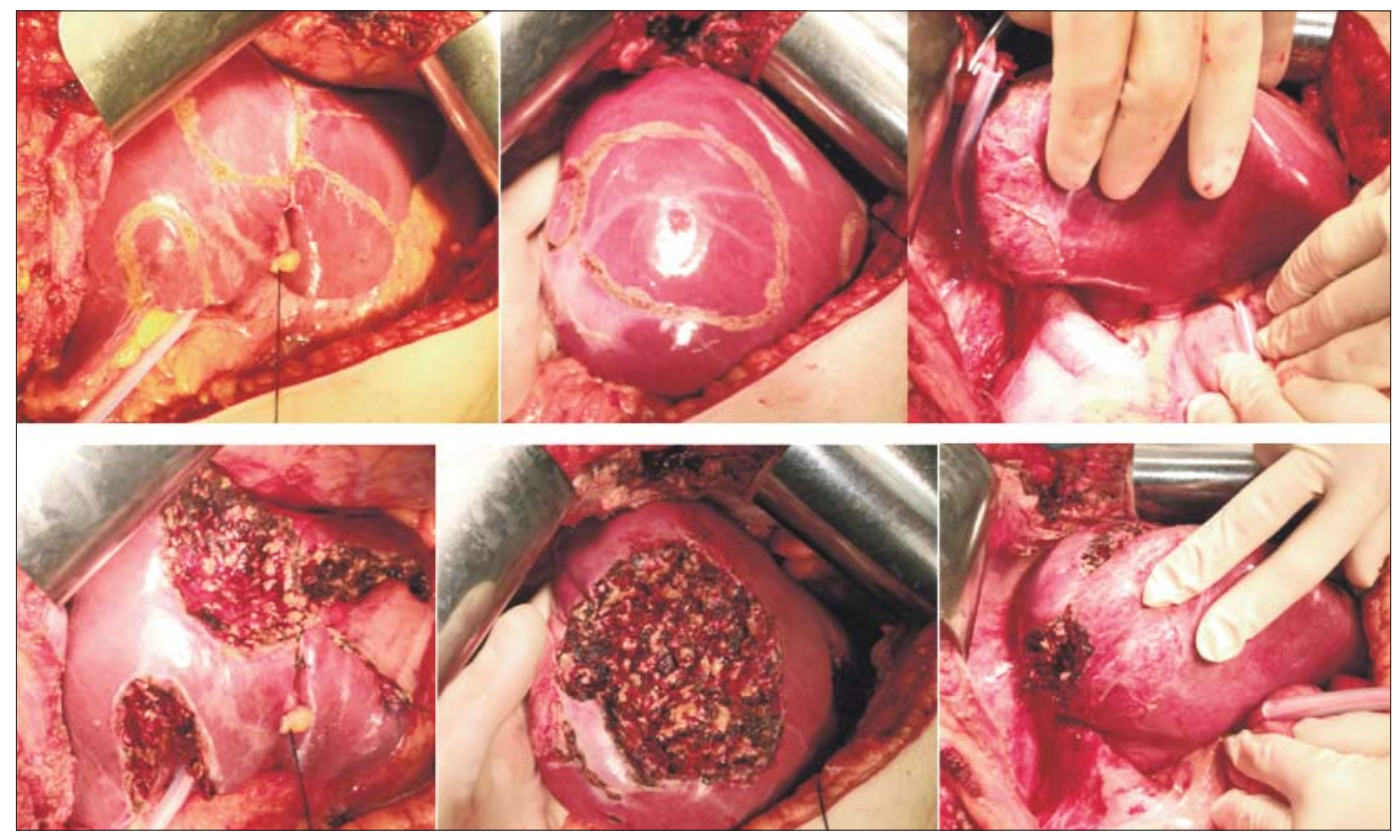

Figure 9. Non-anatomical multiple IOUS guided liver resection for multiple bilobar colorectal liver metastases (9 lesions) 


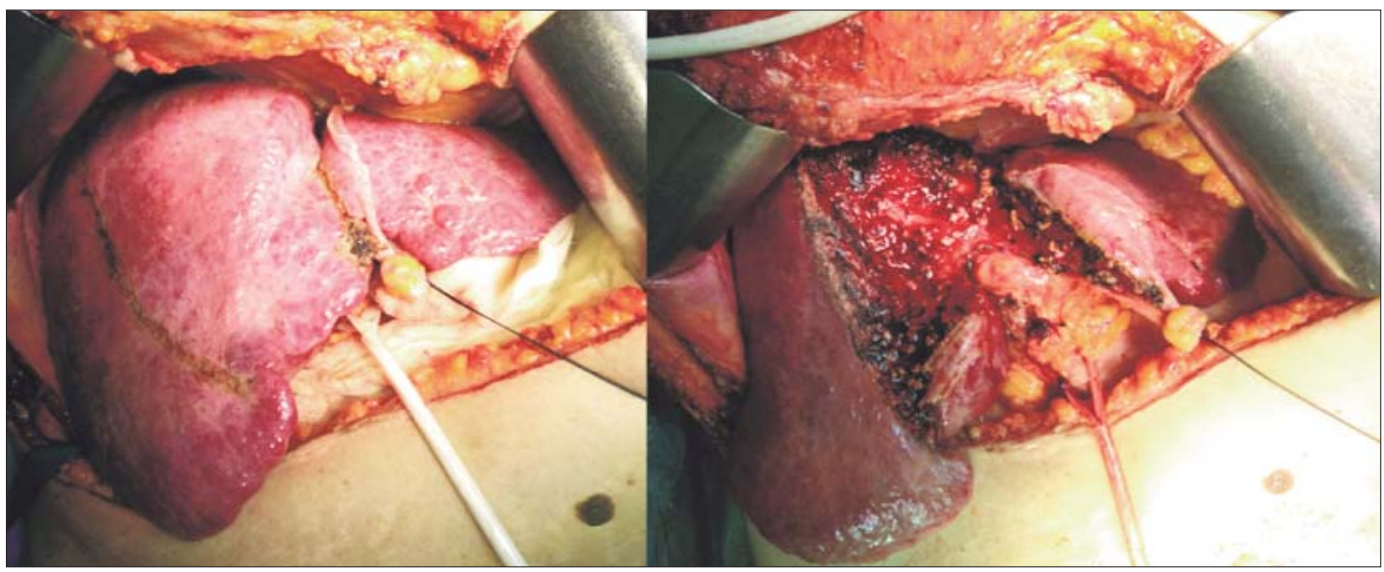

Figure 10 - Non-anatomical IOUS guided liver resection of segments 4, 5 and 8, preserving the P8 and P8d pedicles, for a centrally located hepatocellular carcinoma on Child A liver cirrhosis

involves segmental resection of the middle HV, requires IOUS to detect the presence of compensatory collateral venous circulation towards the right $\mathrm{HV}$ and left HV $(34,65)$. By these techniques, as much as possible liver parenchyma is preserved, enabling LR in some patients considered unresectable by conventional LR techniques.

- LR associated with in-situ ablation of less than 2 $\mathrm{cm}$ tumors located in the FRL.

\section{Postoperative outcome}

LR has been associated with high morbidity and mortality. The reported morbidity has ranged from $16.2 \%$ to $47.7 \%(104,105)$. This large range is partially due to the heterogeneity of the published series, with major differences in indication, extension of hepatic resection, patients with cirrhosis, and criteria for postoperative complication. In our experience, the overall and major complication rates were $46.5 \%$ and $7.6 \%$, respectively, which is in accordance with the published data. Among all liver-related complications, cut surface collection was the most frequent (11.6\%), but in only 2 cases $(1 \%)$ this was a major complication as percutaneous drainage was needed. Of note, the patient with liver failure after $L R$ was transplanted with a whole liver graft, but he died due to neurological complications.

The mortality rate after $L R$ varies from $1.5-3.5 \%$ in high-volume centers, to $8-24 \%$ in low-volume ones $(106,107)$. In our experience, the 90 -day mortality rate was $2 \%$, which is similar to other high-volume centers.

\section{CONCLUSION}

Despite substantial advancements in preoperative imaging, IOUS remains an essential diagnostic tool during surgery, often leading to changes in surgical planning and patient management due to new FLLs not detected preoperatively or more advanced presentation of the preoperatively known FLLs. Accurate evaluation of liver anatomy, precise FLLs localization, characterization, differential diagnosis and local staging, as well as background liver evaluation (steatosis, fibrosis, cirrhosis) are common indication for IOUS. Moreover, real-time guidance of $L R$ and/or ablation techniques, and control of post procedural results, leading to low morbidity and mortality, makes IOUS an essential part of surgical techniques, and therefore should be a standard procedure in liver surgery. Finally, IOUS guidance, integrated in specific policies, insures resectability in patients who otherwise would be submitted to conventional but riskier or incomplete surgery, or would be excluded from curative surgery.

\section{Acknowledgement}

The main author thanks Prof. Guido Torzilli (Humanitas Clinical Institute, Rozzano - Milan, Italy) for the training in liver surgery, particularly in intraoperative ultrasound guided resections.

\section{REFERENCES}

1. Makuuchi M, Torzilli G, Machi J. History of intraoperative ultrasound. Ultrasound Med Biol. 1998;24(9):1229-42.

2. Ellebșk SB, Fristrup CW, Mortensen MB. Intraoperative Ultrasound as a Screening Modality for the Detection of Liver Metastases during Resection of Primary Colorectal Cancer - A Systematic Review. Ultrasound Int Open. 2017;3(2):E60-E68.

3. Torzilli G. Contrast-enhanced intraoperative ultrasonography in surgery for liver tumors. Eur J Radiol. 2004;51 Suppl:S25-9.

4. Charlson M.E., Pompei P., Ales K.L., MacKenzie C.R. A new method of classifying prognostic comorbidity in longitudinal studies: development and validation. J Chronic Dis. 1987;40(5):373-383.

5. Dindo D, Demartines N, Clavien PA. Classification of Surgical 
Complications: A New Proposal With Evaluation in a Cohort of 6336 Patients and Results of a Survey. Ann Surg. 2004;240(2): 205-213.

6. Viganò L, Procopio F, Cimino MM, Donadon M, Gatti A, Costa G, et al. Is Tumor Detachment from Vascular Structures Equivalent to RO Resection in Surgery for Colorectal Liver Metastases? An Observational Cohort. Ann Surg Oncol. 2016;23(4):1352-60. doi: 10.1245/s10434-015-5009-y.

7. Torzilli G, Montorsi M, Donadon M, Palmisano A, Del Fabbro D, Gambetti A, et al. "Radical but conservative" is the main goal for ultrasonography-guided liver resection: prospective validation of this approach. J Am Coll Surg. 2005;201(4):517-28.

8. Torzilli G, Takayama T, Hui AM, Kubota K, Harihara Y, Makuuchi M. A new technical aspect of ultrasound-guided liver surgery. Am J Surg. 1999;178(4):341-3.

9. Kawasaki S, Makuuchi M. Incision for hepatectomy. In: Lygidakis $\mathrm{NJ}$, Makuuchi M, (eds). Pitfalls and complications in the diagnosis and management of hepatobiliary and pancreatic diseases. Stuttgart: George Thieme; 1993. p. 86-88.

10. Terminology Committee of the International Hepato-PancreatoBiliary Association. Liver Resection Guidelines. HPB. 2000; 2(3):333-39.

11. Belghiti J, Guevara OA, Noun R, Saldinger PF, Kianmanesh R. Liver hanging manoeuvre: A safe approach to right hepatectomy without liver mobilization. J Am Coll Surg. 2001:193(1):109-11.

12. Lin TY. A simplified technique for hepatic resection: The crush method. Ann Surg. 1974;180(3):285-90.

13. Aldameh A, McCall JL, Koea JB. Is routine placement of surgical drains necessary after elective hepatectomy? Result from a single institution. J Gastrointest Surg. 2005;9(5):667-71.

14. Sun HC, Qin LX, Lu L, Wang L, Wang L, Ye QH, et al. Randomised clinical trial of the effects of abdominal drainage after elective hepatectomy using the crushing clamp method. Br J Surg. 2006;93(4): 422-6.

15. Choti MA, Sitzmann JV, Tiburi MF, Sumetchotimetha W, Rangsin R, Schulick RD, et al. Trends in long-term survival following liver resection for hepatic colorectal metastases. Ann Surg. 2002;235(6): 759-66.

16. Makuuchi M, Hasegawa $\mathrm{H}$, Yamazaki S, et al. Newly devised probe for intraoperative ultrasonic examination. Image Technol Info Display Med 1979;11:1167-1169.

17. Lane RJ, Glazer G. Intra-operative B-mode ultrasound scanning of the extra-hepatic biliary system and pancreas. Lancet. 1980; 2(8190):334-7.

18. Sigel B, Machi J, Beitler JC, Donahue PE, Bombeck CT, Baker RJ, et al. Comparative accuracy of operative ultrasonography and cholangiography in detecting common duct calculi. Surgery. 1983 94(4):715-20.

19. Castaing D, Kunstlinger F, Habib N, Bismuth $\mathrm{H}$. Intraoperative ultrasonographic study of the liver. Methods and anatomic results. Am J Surg. 1985;149(5):676-82.

20. Bonnet $\mathrm{P}$, Bernard JL, Delmont J, Huguet C. Intraoperative echography: an indispensable element in surgery of small hepatocarcinomas in cirrhotic patients. Ann Chir. 1986;40(9):648-50. French

21. Makuuchi M, Takayama T, Kosuge T, Yamazaki S, Yamamoto J, Hasegawa $\mathrm{H}$, Takayasu K. et al. The value of ultrasonography for hepatic surgery. Hepatogastroenterology. 1991;38(1):64-70.

22. Cho JY, Han HS, Choi Y, Yoon YS, Kim S, Choi JK, et al. Association of remnant liver ischemia with early recurrence and poor survival after liver resection in patients with hepatocellular carcinoma. JAMA Surg. 2017;152(4):386-392. doi: 10.1001/jamasurg.2016.5040.

23. Torzilli G, Makuuchi M. Intraoperative ultrasonography in liver cancer. Surg Oncol Clin N Am. 2003;12(1):91-103.

24. Kruskal JB, Kane RA. Intraoperative ultrasonography of the liver. Crit Rev Diagn Imaging. 1995;36(3):175-226.

25. Kruskal JB, Kane RA. Correlative imaging of malignant liver tumors. Semin Ultrasound CT MR. 1992;13(5):336-54.

26. Finlayson C, Hoffman J, Yeung R, Kessler H, Guttmann M, Shaer A, et al. Intraoperative ultrasound does not improve detection of liver metastases in resectable pancreatic cancer. Am J Surg. 1998; 175(2):99-101.

27. Kruskal JB, Kane RA. Intraoperative US of the liver: techniques and clinical applications. Radiographics. 2006;26(4):1067-84

28. Conlon R, Jacobs M, Dasgupta D, Lodge JP. The value of intraoperative ultrasound during hepatic resection compared with improved preoperative magnetic resonance imaging. Eur J Ultrasound. 2003; 16(3):211-6.

29. Botea $\mathrm{F}$, Ionescu M, Brașoveanu V, Hrehoreț D, Alexandrescu S, Grigorie M, et al. Liver resections in a high-volume center: form standard procedures to extreme surgery and ultrasound-guided resections. Chirurgia (Bucur). 2017;112(3):259-277. doi: 10.21614/ chirurgia.112.3.259

30. Marcal LP, Patnana M, Bhosale P, Bedi DG. Intraoperative abdominal ultrasound in oncologic imaging. World J Radiol. 2013.28;5(3):51-60.

31. Machi J, Schwartz JH, Zaren HA, Noritomi T, Sigel B. Technique of laparoscopic ultrasound examination of the liver and pancreas. Surg Endosc. 1996;10(6):684-9.

32. Clarke MP, Kane RA, Steele G Jr, Hamilton ES, Ravikumar TS, Onik $G$, et al. Prospective comparison of preoperative imaging and intraoperative ultrasonography in the detection of liver tumors. Surgery. 1989;106(5):849-55

33. Knol JA, Marn CS, Francis IR, Rubin JM, Bromberg J, Chang AE. Comparisons of dynamic infusion and delayed computed tomography, intraoperative ultrasound, and palpation in the diagnosis of liver metastases. Am J Surg. 1993; 165(1):81-7; discussion 87-8.

34. Torzilli G, Palmisano A, Procopio F, Cimino M, Botea F, Donadon M, et al. A new systematic small for size resection for liver tumors invading the middle hepatic vein at its caval confluence: minimesohepatectomy. Ann Surg. 2010;251(1):33-9.

35. Millikan KW, Staren ED, Doolas A. Invasive therapy of metastatic colorectal cancer to the liver. Surg Clin North Am. 1997;77(1):27-48.

36. Paul MA, Mulder LS, Cuesta MA, Sikkenk AC, Lyesen GK, Meijer S. Impact of intraoperative ultrasonography on treatment strategy for colorectal cancer. Br J Surg. 1994;81(11):1660-3.

37. Sahani DV, Kalva SP, Tanabe KK, Hayat SM, O'Neill MJ, Halpern EF, et al. Intraoperative US in patients undergoing surgery for liver neoplasms: comparison with MR imaging. Radiology. 2004;232(3): 810-4. Epub 2004 Jul 23.

38. Machi J, Sigel B. Operative ultrasound in general surgery. Am J Surg. 1996;172(1):15-20.

39. Wagnetz U, Atri M, Massey C, Wei AC, Metser U. Intraoperative ultrasound of the liver in primary and secondary hepatic malignancies: comparison with preoperative 1.5-T MRI and 64-MDCT. AJR Am J Roentgenol. 2011;196(3):562-8. doi: 10.2214/AJR.10.4729.

40. Takigawa Y, Sugawara Y, Yamamoto J, Shimada K, Yamasaki S, Kosuge T, et al. New lesions detected by intraoperative ultrasound during liver resection for hepatocellular carcinoma. Ultrasound Med Biol. 2001;27(2):151-6.

41. Torzilli G, Minagawa M, Takayama T, Inoue K, Hui AM, Kubota K, et al. Accurate preoperative evaluation of liver mass lesions without fine needle biopsy. Hepatology. 1999;30(4):889-93.

42. Quaia E, Calliada F, Bertolotto M, Rossi S, Garioni L, Rosa L, et al. Characterization of focal liver lesions with contrast-specific US modes and a sulfurhexafluoride-filled microbubble contrast agent: diagnostic performance and confidence. Radiology. 2004;232(2): 420-30.

43. Torzilli G, Olivari N, Moroni E, Del Fabbro D, Gambetti A, Leoni P, et al. Contrast-enhanced intraoperative ultrasonography in surgery for hepatocellular carcinoma in cirrhosis. Liver Transpl. 2004 Feb;10(2 Suppl 1):S34-8.

44. Torzilli G, Palmisano A, Del Fabbro D, Marconi M, Donadon M, Spinelli $A$, et al. Contrast-enhanced intraoperative ultrasonography during surgery for hepatocellular carcinoma in liver cirrhosis: is it useful or useless? A prospective cohort study of our experience. Ann Surg Oncol. 2007:14(4):1347-55. Epub 2007 Jan 26.

45. Castaing D, Emond J, Kunstlinger F, Bismuth $\mathrm{H}$. Utility of operative ultrasound in the surgical management of liver tumors. Ann Surg. 1986;204(5):600-5

46. Lau WY, Leung KL, Lee TW, Li AK. Ultrasonography during liver resection for hepatocellular carcinoma. Br J Surg. 1993:80(4):493-4.

47. Popescu I, Tulbure D, Ionescu M, Ciurea S, Brașoveanu V, Pietrăreanu $\mathrm{D}$, et al. Liver resection: indication, tehnique, results - analysis of a 445 case serie. Chirurgia (Bucur). 2003;98(1):34-40. 
48. Staren ED. Intraoperative ultrasound. In: Staren ED, Arregui M (eds). Ultrasound for the Surgeon. Philadelphia: Lippincott-Raven Press; 1996.

49. Machi J, Isomoto H, Kurohiji T, Yamashita Y, Shirouzu K, Kakegawa T, et al. Accuracy of intraoperative ultrasonography in diagnosing liver metastasis from colorectal cancer: Evaluation with postoperative follow-up results. World J Surg. 1991;15(4):551-6 discussion 557.

50. Herman K. Intraoperative ultrasound in gastrointestinal cancer. An analysis of 272 operated patients. Hepatogastroenterology. 1996; 43(9):565-70.

51. Haider MA, Leonhardt C, Hanna SS, Tennenhouse J. The role of intraoperative ultrasonography in planning the resection of hepatic neoplasms. Can Assoc Radiol J. 1995;46(2):98-104.

52. Kane RA1, Hughes LA, Cua EJ, Steele GD, Jenkins RL, Cady B. The impact of intraoperative ultrasonography on surgery for liver neoplasms. J Ultrasound Med. 1994;13(1):1-6.

53. Solomon MJ, Stephen MS, Gallinger S, White GH. Does intraoperative ultrasonography change surgical decision making during liver resection? Am J Surg. 1994;168(4):307-10.

54. Bismuth H, Castaing D, Garden OJ. The use of operative ultrasound in surgery of primary liver tumours. World J Surg. 1987;11(5):610-4.

55. Moug SJ, Horgan PG, Leen E. Contrast-enhanced ultrasonography during liver surgery (Br J Surg 2004;91:1165-67). Br J Surg 2004; 91(11):1527.

56. Cerwenka H, Raith J, Bacher H, Werkgartner G, el-Shabrawi A, Kornprat $P$, et al. Is intraoperative ultrasonography during partial hepatectomy still necessary in the age of magnetic resonance imaging? Hepatogastroenterology. 2003;50(53):1539-41.

57. Lin TY. Resectional therapy for primary malignant hepatic tumors. In: MurphyGP, editors. International Advances in Surgical Oncology New York: Alan R Liss; 1979. p. 25-54.

58. Torzilli G, Makuuchi M, Inoue K, Takayama T, Sakamoto Y, Sugawara $Y$, et al. No-mortality liver resection for hepatocellular carcinoma in cirrhotic and noncirrhotic patientsis there a way? A prospective analysis of our approach. Arch Surg. 1999;134(9):984-92.

59. Makuuchi M. Abdominal Intraoperative Ultrasonography. TokyoNew York: Igaku-Shoin; 1987.

60. Minagawa M, Makuuchi M, Takayama T, Ohtomo K. Selection criteria for hepatectomy in patients with hepatocellular carcinoma and portal vein tumor thrombus. Ann Surg. 2001:233(3):379-84

61. Dimick JB, Cowan JA Jr, Knol JA, Upchurch GR Jr. Hepatic resection in the Unites States: indications, outcomes, and hospital procedural volumes from a nationally representative database. Arch Surg. 2003; 138(2):185-91.

62. Blackham AU, Swett K, Levine EA, Shen P. Surgical management of colorectal cancer metastases to the liver: multimodality approach and a single institutional experience. Colorectal Cancer. 2013;2(1): 73-88.

63. Popescu I, Ionescu M, Alexandrescu S, Ciurea S, Hrehoret D, SârbuBoeți P, et al. Surgical treatment of liver metastases from colorectal cancer. Chirurgia (Bucur). 2006; 101(1):13-24. Romanian

64. Torzilli G, Donadon M, Marconi M, Botea F, Palmisano A, Del Fabbro $D$, et al. Systematic extended right posterior sectionectomy: a safe and effective alternative to right hepatectomy. Ann Surg. 2008; 247(4):603-11. doi: 10.1097/SLA.0b.

65. Donadon M, Procopio F, Torzilli G. Tailoring the area of hepatic resection using inflow and outflow modulation. World J Gastroenterol. 2013;19(7):1049-55. doi: 10.3748/wjg.v19.i7.1049.

66. Lai EC, Ng IO, Ng MM, Lok AS, Tam PC, Fan ST, et al. Long term results of resection for large hepato cellular carcinoma: a multivariate analysis of clinicopathological factors. Hepatology. 1990; 11(5):815-8.

67. Lesurtel M, Selzner M, Petrowsky H, McCormack L, Clavien PA. How should transection of the liver be performed? A prospective randomized study in 100 consecutive patients: Comparing four different transection strategies. Ann Surg. 2005;242(6):814-22, discussion 822-3.

68. Bui LL, Smith AJ, Bercovici M, Szalai JP, Hanna SS. Minimising blood loss and transfusion requirements in hepatic resection. HPB (Oxford) 2002;4:5-10. doi: 10.1080/136518202753598672.
69. Pulitano C, Arru M, Bellio L, Rossini S, Ferla G, Aldrighetti L. A risk score for predicting perioperative blood transfusion in liver surgery. Br J Surg. 2007;94:860-5.

70. Kooby DA, Stockman J, Ben-Porat L, Gonen M, Jarnagin WR, Dematteo RP, et al. Influence of transfusions on perioperative and long-term outcome in patients following hepatic resection for colorectal metastases. Ann Surg. 2003;237(6):860-9; discussion 869-70.

71. Asahara T, Katayama K, Itamoto T, Yano M, Hino H, Okamoto Y, et al. Perioperative blood transfusion as a prognostic indicator in patients with hepatocellular carcinoma. World J Surg. 1999;23(7): 676-80.

72. de Boer MT, Molenaar IQ, Porte RJ. Impact of blood loss on outcome after liver resection. Dig Surg. 2007;24(4):259-64. Epub 2007 Jul 27.

73. Wang WD, Liang LJ, Huang XQ, Yin XY. Low central venous pressure reduces blood loss in hepatectomy. World J Gastroenterol. 2006;12(6):935-9.

74. Matsumura M, Mise Y, Saiura A, Inoue Y, Ishizawa T, Ichida $\mathrm{H}$, et al. Parenchymal-Sparing Hepatectomy Does Not Increase Intrahepatic Recurrence in Patients with Advanced Colorectal Liver Metastases. Ann Surg Oncol. 2016;23(11):3718-3726. doi: 10.1245/s10434016-5278-0. Epub 2016 May 20.

75. Moris D, Ronnekleiv-Kelly S, Rahnemai-Azar AA, Felekouras E, Dillhoff M, Schmidt C, et al. Parenchymal-Sparing Versus Anatomic Liver Resection for Colorectal Liver Metastases: a Systematic Review. J Gastrointest Surg. 2017;21(6):1076-1085. doi: 10.1007/ s11605-017-3397-y.

76. Mise Y, Aloia TA, Brudvik KW, Schwarz L, Vauthey JN, Conrad C. Parenchymal-sparing Hepatectomy in Colorectal Liver Metastasis Improves Salvageability and Survival. Ann Surg. 2016;263(1):14652. doi: $10.1097 /$ SLA.0000000000001194.

77. Makuuchi M, Hasegawa H, Yamazaki S. Ultrasonically guided subsegmentectomy. Surg Gynecol Obstet 1985;161:346-50.

78. Makuuchi M, Haseqauna H, Yamazaki S. Intraoperative puncture of the liver guided by ultrasound. In Holms HH, Kristensen J (eds). Interventional Ultrasound. Copenhagen: Munksgaard; 1985. p. 65.

79. Hasegawa K, Kokudo N, Imamura H, Matsuyama Y, Aoki T, Minagawa M, et al. Prognostic impact of anatomic resection for hepatocellular carcinoma. Ann Surg. 2005; 242(2):252-9.

80. Kaibori M, Matsui Y, Hijikawa T, Uchida Y, Kwon AH, Kamiyama Y. Comparison of limited and anatomic hepatic resection for hepatocellular carcinoma with hepatitis C. Surgery. 2006;139(3):385-94.

81. Torzilli G, Donadon M, Cimino M, Del Fabbro D, Procopio F, Botea F. Systematic subsegmentectomy by ultrasound-guided finger compression for hepatocellular carcinoma in cirrhosis. Ann Surg Oncol. 2009;16(7):1843.

82. Sarpel U, Bonavia AS, Grucela A, Roayaie S, Schwartz ME, Labow DM. Does anatomic versus nonanatomic resection affect recurrence and survival in patients undergoing surgery for colorectal liver metastasis? Ann Surg Oncol. 2009;16(2):379-84. doi: 10.1245/ s10434-008-0218-2. Epub 2008 Nov 20.

83. Zorzi D, Mullen JT, Abdalla EK, Pawlik TM, Andres A, Muratore A, et al. Comparison between hepatic wedge resection and anatomic resection for colorectal liver metastases. J Gastrointest Surg. 2006; 10(1):86-94.

84. Cady B, Jenkins RL, Steele GD Jr, Lewis WD, Stone MD, McDermott WV et al. Surgical margin in hepatic resection for colorectal metastasis: a critical and improvable determinant of outcome. Ann Surg. 1998;227(4):566-71.

85. Ekberg H, Tranberg KG, Andersson R, Lundstedt C, Hagerstrand I, Ranstam $\mathrm{J}$ et al. Determinants of survival in liver resection for colorectal secondaries. Br J Surg. 1986;73(9):727-31.

86. Shirabe K, Takenaka K, Gion T, Fujiwara Y, Shimada M, Yanaga K et al. Analysis of prognostic risk factors in hepatic resection for metastatic colorectal carcinoma with special reference to the surgical margin. Br J Surg. 1997;84(8):1077-80.

87. Pawlik TM, Vauthey JN. Surgical margins during hepatic surgery for colorectal liver metastases: complete resection not millimetres defines outcome. Ann Surg Oncol. 2008;15(3):677-9. doi: 10.1245/s10434-007-9703-2. Epub 2007 Dec 29. 
88. Figueras J, Burdio F, Ramos E, Torras J, Llado L, Lopez-Ben S, et al. Effect of subcentimeter nonpositive resection margin on hepatic recurrence in patients undergoing hepatectomy for colorectal liver metastases. Evidences from 663 liver resections. Ann Oncol. 2007; 18(7):1190-5.

89. Shi M, Guo RP, Lin XJ, Zhang YQ, Chen MS, Zhang CQ, et al. Partial hepatectomy with wide versus narrow resection margin for solitary hepatocellular carcinoma: a prospective randomized trial. Ann Surg 2007;245(1):36-43

90. Ochiai T, Takayama T, Inoue K, Yamamoto J, Shimada K, Kosuge T, et al. Hepatic resection with and without surgical margins for hepatocellular carcinoma in patients with impaired liver function. Hepatogastroenterology. 1999;46(27):1885-9.

91. Matsui Y, Terakawa N, Satoi S, Kaibori M, Kitade H, Takai S, et al. Postoperative outcomes in patients with hepatocellular carcinomas resected with exposure of the tumor surface: clinical role of the nomargin resection. Arch Surg. 2007;142(7):596-602; discussion 603

92. de Haas RJ, Wicherts DA, Flores E, Azoulay D, Castaing D, Adam R. $R 1$ resection by necessity for colorectal liver metastases: is it still a contraindication to surgery? Ann Surg. 2008;248(4):626-37.

93. Kokudo N, Miki Y, Sugai S, Yanagisawa A, Kato Y, Sakamoto $Y$ et al. Genetic and histological assessment of surgical margins in resected liver metastases from colorectal carcinoma: minimum surgical margins for successful resection. Arch Surg. 2002;137(7):833-40.

94. Yamamoto J, Sugihara K, Kosuge T, Takayama T, Shimada K, Yamasaki S et al. Pathologic support for limited hepatectomy in the treatment of liver metastases from colorectal cancer. Ann Surg. 1995;221(1):74-8.

95. Popescu I, Alexandrescu S, Croitoru A, Boros M. Strategies to convert to resectability the initially unresectable colorectal liver metastases. Hepatogastroenterology. 2009 May-Jun;56(91-92):739-44.

96. Popescu I, Alexandrescu ST. Surgical options for initially unresectable colorectal liver metastases. HPB Surg. 2012;2012 454026. doi: 10.1155/2012/454026. Epub 2012 Oct 3

97. Torzilli G, Adam R, Viganò L, Imai K, Goransky J, Fontana A, et al. Surgery of colorectal liver metastases: pushing the limits. Liver Cancer. 2016:6(1):80-89.

98. Adam R, Laurent A, Azoulay D, Castaing D, Bismuth H. Two-stage hepatectomy: A planned strategy to treat irresectable liver tumors. Ann Surg. 2000; 232(6):777-85.

99. Popescu I, David L, Brasoveanu V, Boros M, Hrehoret D. Two-stage hepatectomy: an analysis of a single center's experience. Magy Seb. 2006;59(3):184-9.

100. Jaeck D, Oussoultzoglou E, Rosso E, Greget M, Weber JC, Bachellier P. A two-stage hepatectomy procedure combined with portal vein embolization to achieve curative resection for initially unresectable multiple and bilobar colorectal liver metastases. Ann Surg. 2004; 240(6):1037-49; discussion 1049-51.

101. Schnitzbauer AA, Lang SA, Goessmann H, Nadalin S, Baumgart $J$, Farkas $S A$, et al. Right portal vein ligation combined with in situ splitting induces rapid left lateral liver lobe hypertrophy enabling 2-staged extended right hepatic resection in smallfor-size settings. Ann Surg. 2012;255(3):405-14. doi: 10.1097/ SLA.0b013e31824856f5.

102. Torzilli G, Procopio F, Botea F, Marconi M, Del Fabbro D, Donadon M, et al. One-stage ultrasonographically guided hepatectomy for multiple bilobar colorectal metastases: a feasible and effective alternative to the 2-stage approach. Surgery. 2009;146(1):60-71. doi: 10.1016/j.surg. 2009.02.017.

103. Torzilli G, Cimino MM. Extending the Limits of Resection for Colorectal Liver Metastases ENHANCED ONE STAGE SURGERY. J Gastrointest Surg. 2017;21(1):187-189. doi: 10.1007/s11605-016-3250-8.

104. Tsao JI, Loftus JP, Nagorney DM, Adson Ma, Ilstrup DM. Trends in morbidity and mortality of hepatic resection for malignancy: a matched comparative analysis. Ann Surg. 1994;220(2):199-205.

105. Dimick JB, Pronovost PJ, Cowan JA, Lipsett PA. Postoperative complication rates after hepatic resection in Maryland hospitals. Arch Surg. 2003;138:41-46.

106. Choti MA, Bowman HM, Pitt HA, Sosa JA, Sitzmann JV, Cameron JL, Gordon TA. Should hepatic resections be performed at high-volume referral centers? J Gastrointest Surg 1998;2:11-19.

107. Glasgow RE, Showstack JA, Katz PP, Corvera CU, Warren RS, Mulvihill SJ. The Relationship Between Hospital Volume and Outcomes of Hepatic Resection for Hepatocellular Carcinoma. Arch Surg. 1999;134(1):30-5.

108. Eder F, Meyer F, Nestler G, Halloul Z, Lippert H. Sealing of the hepatic resection area using fibrin glue reduces significant amount of post-operative drain fluid. World J Gastroenterol. 2005;14; 11(38):5984-7.

109. Tanaka S, Hirohashi K, Tanaka H, Shuto T, Lee SH, Kubo S, et al. Incidence and management of bile leakage after hepatic resection for malignant hepatic tumors. J Am Coll Surg. 2002;195(4):484-9. 